\title{
What is hidden behind Schiff base hydrolysis? Dynamic covalent chemistry for precise capture of sialylated glycans
}

Yuting Xiong, ${ }^{[\mathrm{a}, \mathrm{b}]}$ Xiuling Li, ${ }^{[\mathrm{a}]}$ Minmin Li, ${ }^{[\mathrm{a}, \mathrm{b}]}$ Haijuan Qin, ${ }^{[\mathrm{c}]}$ Cheng Chen, ${ }^{\mathrm{a}]}$

Dongdong Wang, ${ }^{[\mathrm{a}]}$ Xue Wang, ${ }^{[\mathrm{a}]}$ Xintong Zheng, ${ }^{[\mathrm{a}]}$ Yunhai Liu, ${ }^{[\mathrm{b}]}$ Xinmiao Liang*[a]

Guangyan Qing*[a]

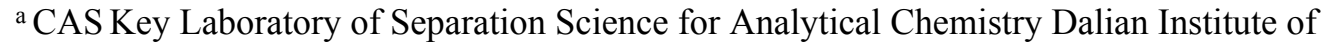

Chemical Physics, Chinese Academy of Sciences, 457 Zhongshan Road, Dalian 116023, P. R.

China

${ }^{\mathrm{b}}$ Jiangxi Province Key Laboratory of Polymer Micro/Nano Manufacturing Devices, East China

University of Technology, 418 Guanglan Avenue, Nanchang 330013, P. R. China

${ }^{\mathrm{c}}$ Research Centre of Modern Analytical Technology, Tianjin University of Science and

Technology, Tianjin, P. R. China

Correspondence authors: Guangyan Qing (Email: qinggy@dicp.ac.cn) and Xinmiao Liang (Email:

liangxm@dicp.ac.cn)

Y. T. Xiong and X. L. Li contribute equally to this work

\section{Supporting Information}




\section{Table of Contents}

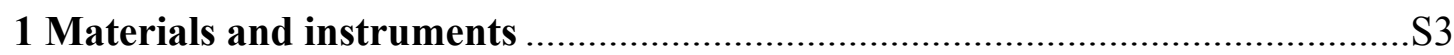

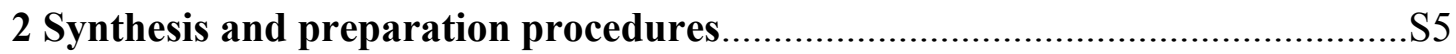

2.1 Synthesis of Glu-Schiff base $@ \mathrm{SiO}_{2}$ and Phenyl-Schiff base $@ \mathrm{SiO}_{2}$.............S5

2.2 Synthesis of 4-[(phenethylimino)methyl]phenyl D-glucopyranoside (Schiff

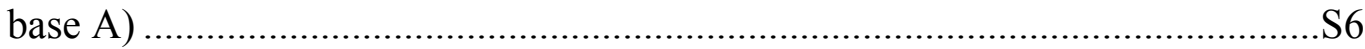

2.3 Preparation of 2-phenylethylamine-Neu5Ac (PEA-Neu5Ac) complex........S7

2.4 Synthesis of Glu-Schiff base on flat $\mathrm{SiO}_{2}$ substrate.......................................S

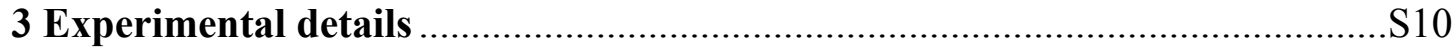

3.1 Trypsin digestion of standard proteins and human serum ..........................S10

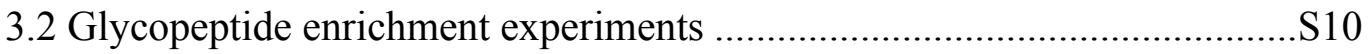

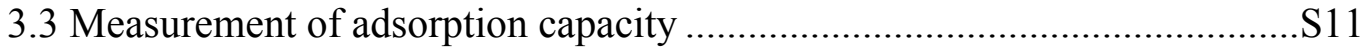

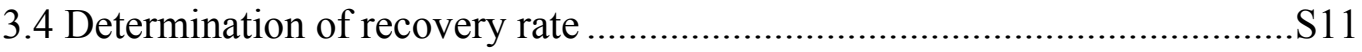

3.5 Mass spectrometer analysis and database search....................................S12

3.6 Isothermal titration microcalorimetry (ITC) experiments .........................S13

3.7 Surface contact angle (CA) measurements .................................................... 13

3.8 Atomic force microscope (AFM) experiments .........................................S14

3.9 X-ray diffraction (XRD) experiments......................................................... 14

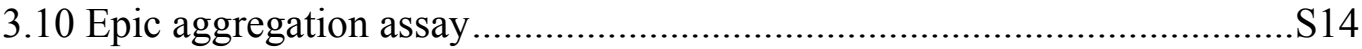

3.11 Surface enhanced Raman spectroscopy (SERS) experiments ...................S15

4 Analysis of sialylated disaccharide triggered Schiff base hydrolysis. ..............S16

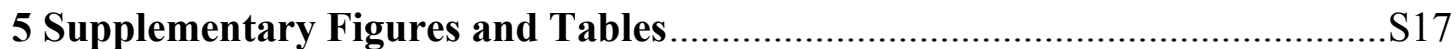

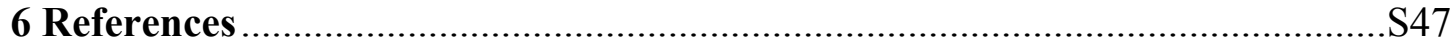




\section{Materials and instruments}

3-Aminopropyl trimethoxysilane (ATMS), 4-formylphenyl $\beta$ - $D$-glucopyranoside, 2-phenylethylamine (PEA), triethylamine (TEA), silver nitrate $\left(\mathrm{AgNO}_{3}\right)$, octanoic acid and sodium citrate were purchased from Alfa Aesar Corp. (Tianjin, China). 4mercaptophenylboric acid (MPBA), benzaldehyde, bovine fetuin, bovine serum albumin (BSA), Sepharose CL-6B, zwitterionic hydrophilic interaction chromatography (ZIC-HILIC) material, ammonium bicarbonate $\left(\mathrm{NH}_{4} \mathrm{HCO}_{3}\right)$, DLdithothreitol (DTT), iodoacetamide (IAA), formic acid (FA), benzylamine- $\mathrm{N}^{15}$ and ammonium hydroxide (28\% 30\%) were purchased from Sigma-Aldrich Corp. (St. Louis, MO, USA). Silica microspheres (average diameter $5 \mu \mathrm{m}$ and inner pore size $300 \AA$ ) were purchased from Fuji Silysia Chemical Ltd. (Aichi, Japan). GELoader tips were ordered from Eppendorf Corp. (Madison, WI, Germany). Glucose, $N$-acetylneuraminic acid (Neu5Ac), Neu5Ac $\alpha(2-3)$ GalßMP glycoside (CAS No. 159922-54-0) and sialylglycopeptide (CAS No. 189035-43-6) were purchased from Tokyo Chemical Industry (TCI) Co., Ltd (Tokyo, Japan). Acetonitrile $\left(\mathrm{CH}_{3} \mathrm{CN}\right)$, methanol $\left(\mathrm{CH}_{3} \mathrm{OH}\right)$ and ethanol $\left(\mathrm{C}_{2} \mathrm{H}_{5} \mathrm{OH}\right)$ were of chromatographic pure. Other solvents and reaction reagents were purchased from Sinopharm Chemical Reagent Co., Ltd. (China). Water used in this study was ultrapure water $(18.2 \mathrm{M} \Omega \cdot \mathrm{cm})$ obtained from Milli-Q system.

All nuclear magnetic resonance (NMR) spectra were recorded on a Bruker Avance III 400 NMR spectrometer. Scanning electron microscope (SEM) image was obtained by Hitachi S-4800 (Hitachi, Ltd., Japan). Fourier translation infrared spectra (FT-IR) were recorded on a Bruker Optics Vertex 80v FT-IR spectrometer. X-ray photoelectron spectroscopy (XPS) was obtained with a VG Multilab 2000. Atomic force microscopy (AFM) investigation was conducted using a JPK NanoWizard Ultra Speed AFM\&inVia Raman system. Isothermal titration microcalorimetry (ITC) experiment was conducted on a MicroCal ITC 200 system (Malvern Panalytical Ltd., 
UK). Mass spectra (MS) were acquired with a nano electrospray ionizationquadrupole time-of-flight mass spectrometer (ESI Q-TOF MS) and LTQ Orbitrap Velos coupled with Accela 600 HPLC system. Atomic force microscopy (AFM) investigation was recorded on a NanoWizard Ultra Speed AFM (JPK Instruments, Germany). Raman spectroscopy was carried out on a Renishaw InVia Raman. X-ray diffraction (XRD) was conducted on a PANalytical X'Pert PRO X-ray (Philips, Japan) diffractometer with $\mathrm{Cu} \mathrm{K} \alpha$ radiation source $(\lambda=1.54059 \AA)$. Molecule selfassembly was investigated by the Label-free Corning ${ }^{\circledR}$ Epic ${ }^{\circledR}$ technology $(\mathrm{NY}$, USA). Separation and purification of the PEA-Neu5Ac complex were performed on a Shimadzu LC-20AT High Performance Liquid Chromatography (HPLC) using a home-made Click TE-Cys semi-preparative column $(10 \mathrm{~mm} \times 250 \mathrm{~mm})$. Static contact angles were measured through KRUSS DSA 100 (KRÜSS GmbH, Germany) at ambient atmosphere and a constant temperature of $25^{\circ} \mathrm{C}$. 


\section{Synthesis and preparation procedures}

\subsection{Synthesis of Glu-Schiff base $@ \mathrm{SiO}_{2}$ and Phenyl-Schiff base@SiO}
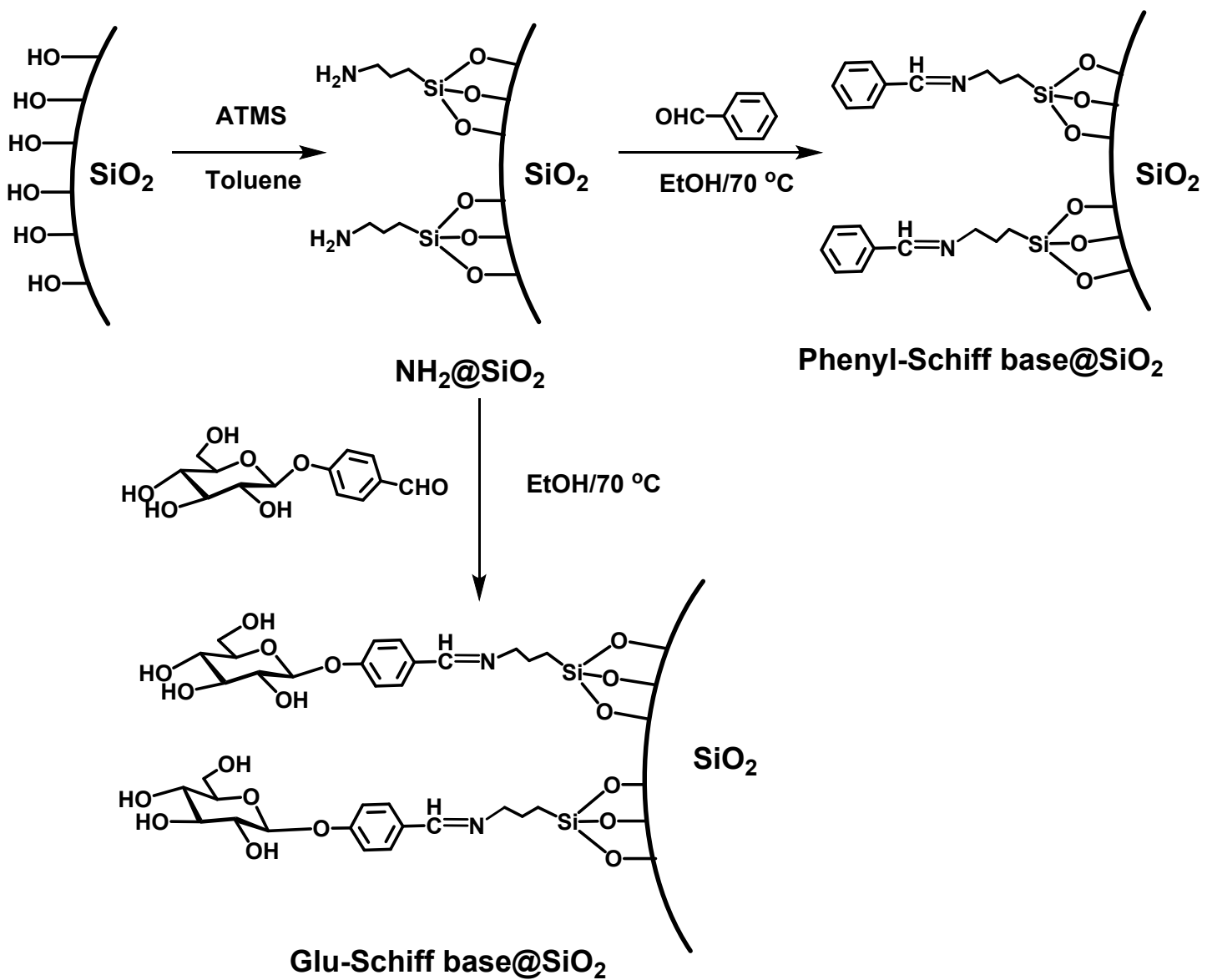

Phenyl-Schiff base@SiO 2

Glu-Schiff base@SiO 2

Scheme S1. Synthesis of $\mathrm{NH}_{2} @ \mathrm{SiO}_{2}$, Phenyl-Schiff base@ $\mathrm{SiO}_{2}$ and Glu-Schiff base@ $\mathrm{SiO}_{2}$

Silica gels $(5.0 \mathrm{~g})$ were suspended in $25 \mathrm{~mL}$ of hydrochloric acid $(\mathrm{HCl}, 0.1$ $\mathrm{mol} \cdot \mathrm{L}^{-1}$ ) for 48 hours to generate sufficient hydroxyl groups on the silica gel surface. Subsequently, the hydroxylated silica gels were separated by centrifugation at 7000 rpm for $5 \mathrm{~min}$ and washed with ultrapure water and ethanol for three times, then were dried under vacuum. Then, the hydroxylated silica gels $(3.0 \mathrm{~g})$ were added to anhydrous toluene $(60 \mathrm{~mL})$ containing 3-aminopropyltrimethoxysilane (ATMS, 5 $\mathrm{mL})$. The reaction mixture was stirred and refluxed for 24 hours. The obtained aminomodified silica gels (denoted as $\mathrm{NH}_{2} @ \mathrm{SiO}_{2}$ ) were separated by centrifugation at 7000 rpm for 5 min and washed three times with toluene as well as ethanol by repetitive 
dispersion/precipitation cycles to remove residual ATMS. After that, the $\mathrm{NH}_{2} @ \mathrm{SiO}_{2}$ were dried under vacuum. ${ }^{1}$

The $\mathrm{NH}_{2} @ \mathrm{SiO}_{2}(2.0 \mathrm{~g})$, 4-formylphenyl- $\beta$-D-glucopyranoside (0.4 g) and triethylamine $(200 \mu \mathrm{L})$ were added into dry ethanol $(10 \mathrm{~mL})$. The mixture solution was stirred for 12 hours at room temperature. ${ }^{2}$ Then, Glu-Schiff base $@ \mathrm{SiO}_{2}$ gels were obtained after a washing process successively with ultrapure water and ethanol via repetitive dispersion/precipitation cycles to remove the residual chemicals. Glu-Schiff base@ $\mathrm{SiO}_{2}$ silica gels were dried under vacuum. Similar method was used to prepare the Phenyl-Schiff base@ $\mathrm{SiO}_{2}$.

\subsection{Synthesis of 4-[(phenethylimino)methyl]phenyl D-glucopyranoside (Schiff}

\section{base $\mathrm{A})$}

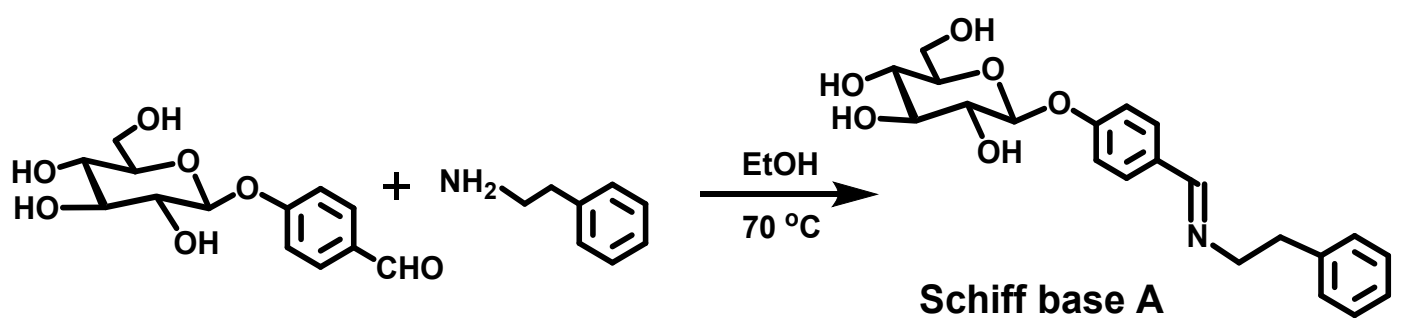

Scheme S2. Synthesis of 4-[(phenethylimino)methyl]-phenyl D-glucopyranoside (Schiff base A)

2-Phenylethylamine (PEA, $125 \mu \mathrm{L}, 1 \mathrm{mmol}$ ) and 4-formylphenyl- $\beta$-Dglucopyranoside $(0.284 \mathrm{~g}, 1 \mathrm{mmol})$ were added to dry ethanol $(30 \mathrm{~mL})$. The mixture solution was stirred at $70{ }^{\circ} \mathrm{C}$ for 12 hours. ${ }^{3}$ Then, the solution was evaporated under reduced pressure, and the residue was recrystallized from hexane: ether $(\mathrm{v} / \mathrm{v}=5 / 1)$ to give 4-[(phenethylimino)methyl]-phenyl D-glucopyranoside (denoted as Schiff base A) as a light yellow solid (0.367 g, yield: $95 \%)$. Characterization of the Schiff base A: ${ }^{1} \mathrm{H}$ NMR (400 MHz, DMSO- $\left.d_{6}\right): \delta(\mathrm{ppm}): 8.20(\mathrm{~s}, 1 \mathrm{H}, \mathrm{CH}=\mathrm{N}), 7.65(\mathrm{~d}, J=6.6 \mathrm{~Hz}, 2 \mathrm{H}$, Ph- $H$ ), 7.36-7.14 (m, 5H, Ph- $H$ ), 7.05 (d, $J=6.7$ Hz, 2H, Ph- $H$ ), 5.17 (d, J=6.3 Hz, 1H, CH-O), $5.11(\mathrm{~d}, J=5.4 \mathrm{~Hz}, 1 \mathrm{H}, \mathrm{CH}-\mathrm{OH}), 4.98$ (d, J=2.9 Hz, 1H, CH-OH). 4.68 (d, 
$J=5.9 \mathrm{~Hz}, 1 \mathrm{H}, \mathrm{CH}-\mathrm{OH}), 4.52(\mathrm{t}, J=4.6 \mathrm{~Hz}, 1 \mathrm{H}, \mathrm{CH}-\mathrm{OH}), 3.93$ (t, $J=3.3 \mathrm{~Hz}, 1 \mathrm{H}, \mathrm{CH}-$ $\mathrm{OH}), 3.77$ (t, $\left.J=5.8 \mathrm{~Hz}, 2 \mathrm{H}, \mathrm{N}-\mathrm{CH}_{2}\right), 3.74-3.64$ (m, 2H, CH-OH), 3.44 (m, 3H, CH$\mathrm{OH}), 2.91\left(\mathrm{t}, J=5.8 \mathrm{~Hz}, 2 \mathrm{H}, \mathrm{CH}_{2}-\mathrm{Ph}\right) .{ }^{13} \mathrm{C} \mathrm{NMR}\left(100 \mathrm{MHz}, \mathrm{DMSO}-d_{6}\right): \delta(\mathrm{ppm})$ : $160.7,159.9,140.5,130.4,129.7,129.3,128.7,126.4,116.6,98.7,75.2,72.0,70.7$, 67.5, 62.4, 61.4, 37.5. IR (cm-1): 3334, 2890, 1643, 1604, 1581, 1509, 1453, 1304, 1234, 1172, 1077, 1035, 877, 833, 748, 699. Elemental analysis, calcd. (\%) for $\mathrm{C}_{21} \mathrm{H}_{25} \mathrm{NO}_{6}$ : C, 65.10; H, 6.50; N, 3.62; found C, 65.02; H, 6.36; N, 3.73; MALDIMS: m/z calcd. for $\mathrm{C}_{21} \mathrm{H}_{25} \mathrm{NO}_{6}: 387.17$; found: $388.17[\mathrm{M}+\mathrm{H}]^{+}$.

\subsection{Preparation of 2-phenylethylamine-Neu5Ac (PEA-Neu5Ac) complex}

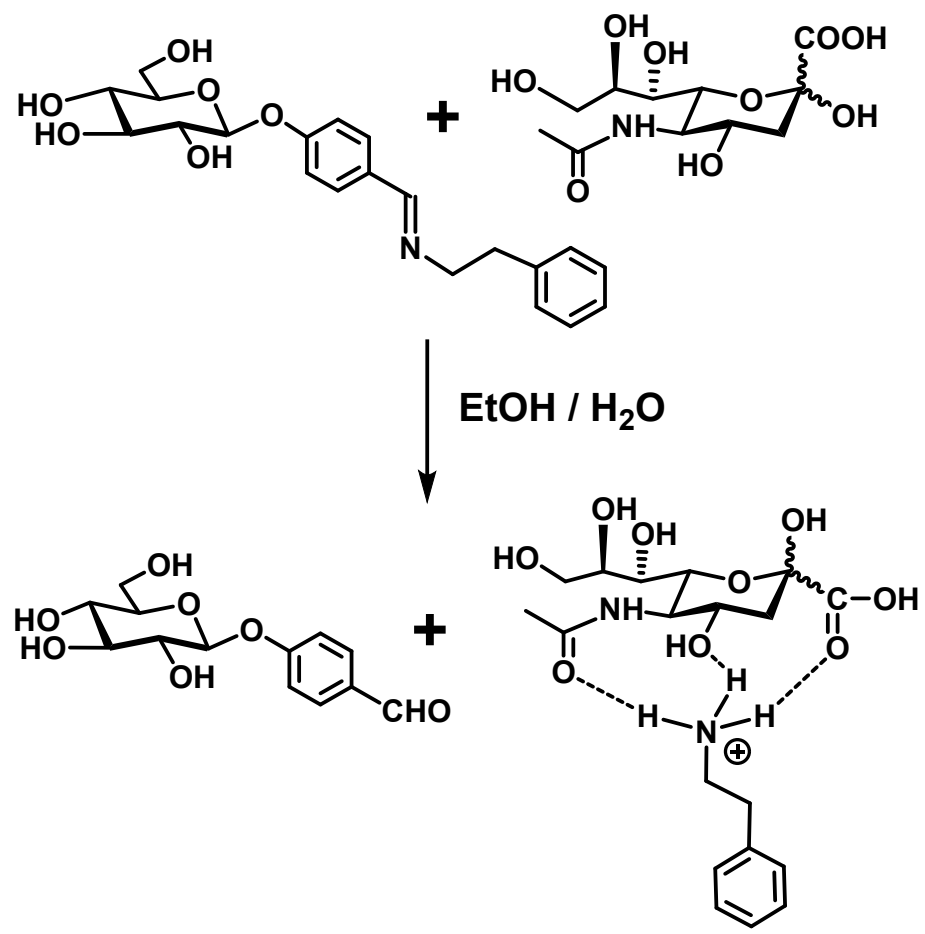

Scheme S3. Preparation of the PEA-Neu5Ac complex

Neu5Ac (31 mg, $0.1 \mathrm{mmol})$ and 4-[(phenethylimino)methyl]phenyl Dglucopyranoside $(39 \mathrm{mg}, 0.1 \mathrm{mmol})$ were added to ethanol $(10 \mathrm{~mL})$. The mixture solution was stirred at room temperature for 12 hours. Then, the crude product was concentrated under reduced pressure, and purified by a home-made hydrophilic column (Click TE-Cys semi-preparative liquid chromatography column, $250 \times 10$ $\mathrm{mm}$ ) with a linear gradient of the binary solvent system of water (solvent A) and 
acetonitrile (solvent B), a linear gradient of $90 \%-50 \%$ B over 20 min at a flow rate of $3 \mathrm{~mL} \cdot \mathrm{min}^{-1}$. And, the semi-preparative liquid chromatography column was set to $30{ }^{\circ} \mathrm{C}$ and the wavelength of UV detection was set as $195 \mathrm{~nm}$. The PEA-Neu5Ac complex was collected from $16 \sim 17 \mathrm{~min}$ and obtained as white solid after freeze drying (34 mg). ${ }^{1} \mathrm{H}$ NMR (400 MHz, $\left.\mathrm{D}_{2} \mathrm{O}\right): \delta(\mathrm{ppm}): 7.34$ (t, $J=7.4 \mathrm{~Hz}, 2 \mathrm{H}, \mathrm{Ph}-H$ ), 7.27 (m, 3H, Ph-H), 3.99-3.87 (m, 2H, -CH-), 3.86-3.79 (m, 1H, CH-NH), 3.79-3.69 (m, 2H, CH-OH), 3.68-3.61 (m, 1H, CH-OH), 3.52-3.46 (m, 1H, CH-OH), 3.43 (m, 1H, CH-OH), 3.20 (t, J=7.3 Hz, 2H, $\left.\mathrm{CH}_{2}-\mathrm{NH}\right), 2.92$ (t, J=7.3 Hz, 2H, CH$H_{2}-\mathrm{Ph}$ ), 2.13 $\left(\mathrm{dd}, J_{1}=J_{2}=12.9 \mathrm{~Hz}, 1 \mathrm{H},-\mathrm{CH}-\right), 1.96\left(\mathrm{~s}, 3 \mathrm{H}, \mathrm{CH}_{3}-\mathrm{CO}\right), 1.73\left(\mathrm{dd}, J_{1}=12.9 \mathrm{~Hz}, J_{2}=11.4\right.$ $\mathrm{Hz}, 1 \mathrm{H},-\mathrm{CH}-) .{ }^{13} \mathrm{C}$ NMR (100 MHz, $\left.\mathrm{D}_{2} \mathrm{O}\right): \delta$ (ppm): 176.5, 174.7, 136.6, 129.0, $128.9,127.3,96.3,70.3,70.2,68.5,67.2,63.2,52.2,40.6,39.3,32.7,22.1$. IR $\left(\mathrm{cm}^{-1}\right)$ : 3243, 2919, 1594, 1371, 1206, 1126, 1068, 1026, 943, 899, 892, 841, 776, 747, 698. Elemental analysis, calcd. (\%) for $\mathrm{C}_{19} \mathrm{H}_{30} \mathrm{~N}_{2} \mathrm{O}_{9}$ : C, 52.89; H, 7.24; N, 6.49; found C, 52.76; H, 7.17; N, 6.63; MADLI-MS: m/z calcd. for $\mathrm{C}_{19} \mathrm{H}_{30} \mathrm{~N}_{2} \mathrm{O}_{9}$ : 430.20; found: $431.21[\mathrm{M}+\mathrm{H}]^{+}$.

\subsection{Synthesis of Glu-Schiff base on flat $\mathrm{SiO}_{2}$ substrate}

A clean monocrystalline silicon wafer was immersed in a sodium hydroxide $\left(\mathrm{NaOH}, 0.1 \mathrm{~mol} \cdot \mathrm{L}^{-1}\right)$ aqueous solution for $5 \mathrm{~min}$ and subsequently in a nitric acid $\left(\mathrm{HNO}_{3}, 0.1 \mathrm{~mol} \cdot \mathrm{L}^{-1}\right)$ aqueous solution for $10 \mathrm{~min}$ to generate surface hydroxyl groups. After that the silicon wafer was washed with an excess of water and ethanol, then was dried under a $\mathrm{N}_{2}$ flow. The hydroxylated wafer was heated to reflux in dry toluene that contained $5 \mathrm{wt} \%$ ATMS for 3 hours to obtain chemically bonded amine groups on the surface $\left(\mathrm{NH}_{2}-\mathrm{SiO}_{2}\right.$ surface $) .{ }^{4}$ The wafer was rinsed with dry toluene and dichloromethane to remove remaining ATMS, then the surface was dried under $\mathrm{N}_{2}$ flow.

Subsequently, $\mathrm{NH}_{2}-$ modified silicon wafer was immersed in a solution of 4formylphenyl- $\beta$-D-glucopyranoside $(0.2 \mathrm{~g})$ in dry ethanol $(5.0 \mathrm{~mL})$, the solution was 
heated to $40{ }^{\circ} \mathrm{C}$ for 6 hours. After that, the reaction was stopped by removing the substrate from the solution, the obtained Glu-Schiff base modified flat $\mathrm{SiO}_{2}$ substrate was washed with methanol, DMF and water, respectively, then dried under $\mathrm{N}_{2}$ flow, which served as an equivalent 2D surface of Glu-Schiff base@ $\mathrm{SiO}_{2}$ to carry out the surface contact angle measurement. Similar method was used to prepare the PhenylSchiff base on the flat $\mathrm{SiO}_{2}$ substrate. 


\section{Experimental details}

\subsection{Trypsin digestion of standard proteins and human serum}

Standard proteins and human serum were provided by the Second Affiliated Hospital of Dalian Medical University. Serum proteins in human serum were precipitated with three volume folds of cold $\mathrm{CH}_{3} \mathrm{CN}$ and kept in $-20^{\circ} \mathrm{C}$ overnight. After centrifugation at $10000 \mathrm{~g}$ for $20 \mathrm{~min}$, the supernatants were removed and serum proteins were left. Proteins including bovine fetuin, bovine serum albumin (BSA) or serum proteins $(1 \mathrm{mg})$ was dissolved with urea aqueous solution $(6 \mathrm{M}, 100 \mu \mathrm{L})$ containing $50 \mathrm{mM} \mathrm{NH}_{4} \mathrm{HCO}_{3}(\mathrm{pH} 8.2)$, respectively. The disulfide bonds in proteins were disrupted with $2 \mu \mathrm{L}$ of $200 \mathrm{mM}$ DTT in a buffer of $50 \mathrm{mM} \mathrm{NH}_{4} \mathrm{HCO}_{3}(\mathrm{pH}$ 8.2). The resulting solution was incubated at $56{ }^{\circ} \mathrm{C}$ for $45 \mathrm{~min}$, and then $5 \mu \mathrm{L}$ of $100 \mathrm{mM}$ IAA in $50 \mathrm{mM} \mathrm{NH}_{4} \mathrm{HCO}_{3}(\mathrm{pH} 8.2)$ was added. The solution was stored in the dark for $30 \mathrm{~min}$ at room temperature. After that trypsin was used to digest protein at a ratio of 1:30 (protein: enzyme). The digestion was performed at $37^{\circ} \mathrm{C}$ for 16 hours, finally the reaction was stopped by adding FA to the final concentration of $1 \% .{ }^{5}$ For the digests mixture of fetuin and BSA at molar ratios of 1:10 (Sample 1), 1:200 (Sample 2), and 1:5000 (Sample 3), $10 \mu \mathrm{L}$ of bovine fetuin digests $\left(26.0 \mathrm{pmol} \cdot \mu \mathrm{L}^{-1}\right)$ were mixed with $180.0 \mu \mathrm{L}, 3600 \mu \mathrm{L}$ or $90200 \mu \mathrm{L}$ of BSA $\left(14.4 \mathrm{pmol} \cdot \mu \mathrm{L}^{-1}\right)$, respectively. These three samples were desalted with $\mathrm{C} 18$ packed solid phase extraction columns (gifts from Acchrom Company, P. R. China). The desalted peptides were dried with Speed Vacuum and redissolved with $200 \mu \mathrm{L}$ of $85 \% \mathrm{CH}_{3} \mathrm{CN} / 1 \% \mathrm{FA}$.

\subsection{Glycopeptide enrichment experiments}

The enrichment of glycopeptides was carried out in a microscale solid phase extraction (mSPE) protocol by using different enrichment materials including GluSchiff base@SiO 2 , Phenyl-Schiff base@SiO $\mathrm{Sin}_{2}$ and $\mathrm{NH}_{2} @ \mathrm{SiO}_{2}$, respectively.200 $\mu \mathrm{L}$ tryptic digestion of bovine fetuin at different molar ratios of BSA interference (e.g., 
1:10, 1:200, and 1:5000) were loaded onto the enrichment materials. The enrichment materials were subsequently rinsed with $85 \% \mathrm{CH}_{3} \mathrm{CN} / 1 \% \mathrm{FA}(\mathrm{pH}=2.15)$ and $80 \%$ $\mathrm{CH}_{3} \mathrm{CN} / 1 \% \mathrm{FA}(\mathrm{pH}=2.15)$, and then eluted with $10 \% \mathrm{NH}_{3} \cdot \mathrm{H}_{2} \mathrm{O}$. In addition, the tryptic digestion of bovine fetuin at different molar ratios of BSA interference were loaded onto Glu-Schiff base@ $\mathrm{SiO}_{2}$ and washed according to the aforementioned experimental conditions with minor modification (Table S1).

The glycopeptide enrichment from human serum was carried out in accordance with the condition of fetuin to BSA at a molar ratio of 1:5000. The eluted glycopeptides fractions were treated with PNgase F to remove glycans.

\subsection{Measurement of adsorption capacity}

To determine the adsorption capacity of Glu-Schiff base@ $\mathrm{SiO}_{2}, 1 \mathrm{mg}$ sialylglycopeptide (CAS: 189035-43-6) was dissolved in $20 \mathrm{~mL} \mathrm{75 \%} \mathrm{CH}_{3} \mathrm{CN} / 0.1 \%$ TFA $\left(0.05 \mu \mathrm{g} \cdot \mu \mathrm{L}^{-1}\right)$. Then, a series of $40 \mu \mathrm{L}$ reconstituted solution were successively loaded into a SPE column packed with $1 \mathrm{mg}$ enrichment materials. Each elution fraction from the micro-column was collected and analyzed with Q-TOF MS. Before the point of the adsorption capacity, no sialylglycopeptide signal could be detected in the elution fraction. When the amount of sialylglycopeptide sample loaded into the SPE column was beyond the adsorption capacity, the target signal could be detected. The adsorption capacity was determined before the point that the target sialylglycopeptide signal was detected. Utilizing the same method, the adsorption capacities of Phenyl-Schiff base $@ \mathrm{SiO}_{2}$ and $\mathrm{NH}_{2} @ \mathrm{SiO}_{2}$ were also measured.

\subsection{Determination of recovery rate}

To evaluate the recovery rate of the established method based on Glu-Schiff base@ $\mathrm{SiO}_{2}$ towards glycopeptides, stable-isotope dimethyl labeling method was utilized $^{6}$ and tryptic digestion of bovine fetuin was used as a model sample. The light labelled sialylated glycopeptide (e.g., $m / z$ : $983.7892(3+)$ or $1475.0836(2+)$ ) was 
enriched with Glu-Schiff base@ $\mathrm{SiO}_{2}$. Then the enriched light labelled sialylated glycopeptide was equally mixed with the untreated heavily labelled one. The recovery rate was calculated based on the relative signal of light and heavily labelled sialylated glycopeptide. This experiment was repeated for three times, and an average recovery rate was obtained (Table S4).

\subsection{Mass spectrometer analysis and database search}

The obtained peptide fractions from the tryptic digestion of standard proteins were analyzed with a nano electrospray ionization-quadrupole time-of-flight mass spectrometer (ESI Q-TOF MS, Waters, and Milford, MA, USA). The peptides were directly infused into ESI source with Nano Acquity UPLC (Waters, Milford, MA, USA). The positive MS scan was acquired at m/z 600-2000 and 100-2000 for full scan and tandem mass scan, respectively.

The PNGase F treated glycopeptide fractions from human serum were separated and identified with LTQ-Orbitrap Velos coupled with Accela 600 HPLC system (Thermo, San Jose, CA). The used mobile phases were $0.1 \%$ FA in water (A) and $0.1 \%$ FA in $\mathrm{CH}_{3} \mathrm{CN}$ (B). Peptides dissolved in $0.1 \%$ FA were firstly loaded onto $\mathrm{C} 18$ trap column (Daisogel, Japan, $200 \mu \mathrm{m} \times 40 \mathrm{~mm}$, average particle size: $5 \mu \mathrm{m}$, average pore diameter: $120 \AA$ ) and separated with C18 analytical column (Daisogel, Japan, 75 $\mu \mathrm{m} \times 120 \mathrm{~mm}$, average particle size: $3 \mu \mathrm{m}$, average pore diameter: $120 \AA$ ). A 106 minute gradient elution was used with $5-22 \% \mathrm{~B}$ in $60 \mathrm{~min}, 22-35 \% \mathrm{~B}$ in $30 \mathrm{~min}, 35-$ $80 \% \mathrm{~B}$ in $10 \mathrm{~min}, 80 \% \mathrm{~B}$ in $6 \mathrm{~min}$. Acquisition of full scan mass data were performed at the mass range from $\mathrm{m} / \mathrm{z} 400$ to $2000(\mathrm{R}=60,000$ at $\mathrm{m} / \mathrm{z} 400)$. The 10 most intense ions from the full scan were selected for collision induced dissociation (CID) in the ion trap. The dynamic exclusion function was set as follows: repeat count 1 , repeat duration $30 \mathrm{~s}$, and exclusion duration of $60 \mathrm{~s}$.

The RAW files collected by Xcalibur 2.1 were converted to *.MGF by Proteome Discoverer (v1.2.0.208, Thermo, San Jose, CA) and searched with Mascot (version 
2.3, Matrix Science, London, UK) using Uniprot protein fasta database of human (88473 entries). Cysteine carboxamidomethylation (C) was set as a fixed modification, oxidation on methionine (M) and deamidation (NQ) were set as the variable modifications. Up to two missing cleavages of trypsin were allowed. Mass tolerances were set as $10 \mathrm{ppm}$ and $0.1 \mathrm{Da}$ for the parent and fragment ions, respectively. A false discovery rate (FDR) of 1\% was set for peptide identification and glycosylation site location. In addition, deglycosylated peptides should have at least six amino acids in length and with the consensus sequence $(\mathrm{N}-\mathrm{X}-\mathrm{S} / \mathrm{T})(\mathrm{X} \neq \mathrm{P})$. Moreover, the localization of the $N$-glycosylation site was further determined by a mass increase of $0.984 \mathrm{Da}$.

\subsection{Isothermal titration microcalorimetry (ITC) experiments}

ITC experiments were performed by Microcal ITC 200 (Malvern Panalytical). 4[(phenethylimino)methyl]phenyl D-glucopyranoside (denoted as Schiff base A) (2 $\mathrm{mM})$ and Neu5Ac (20 mM) were respectively dissolved in distilled water sufficiently to prepared work solutions. The Neu5Ac solution was loaded into the syringe, and titrated into the calorimetric cell containing the Schiff base A solution. The reference cell was filled with Milli-Q water. The temperature is set to $25^{\circ} \mathrm{C}$. The titration sequence consisted of a single $0.4 \mu \mathrm{L}$ injection followed by a series of $2 \mu \mathrm{L}$ solution, with a time interval of 120 s between injections to ensure that the thermal power returns to the baseline before the next injection. The stirring speed was $1000 \mathrm{rpm}$. The released heat was recorded during the reaction process.

In addition, the heat releases of the Schiff base A titrated with glucose and octanoic acid were also measured using the same method. ${ }^{7}$

\subsection{Surface contact angle (CA) measurements}

Static contact angle was measured at ambient atmosphere and a constant temperature of $25^{\circ} \mathrm{C}$. Before measurement, a flat silica substrate modified Glu-Schiff 
base (abbreviated as Glu-Schiff base $@ \mathrm{SiO}_{2}$ ) was cleaned with water and then dried under $\mathrm{N}_{2}$ flow. The static $\mathrm{CA}$ was recorded for each substrate using the sessile drop method and ultrapure water as a solvent. Each measurement was repeated three times to ensure the reliability of data. The same CA measurement on Phenyl-Schiff base@ $\mathrm{SiO}_{2}$ (2D silica surface) and $\mathrm{NH}_{2} @ \mathrm{SiO}_{2}$ (2D silica surface) were also conducted. ${ }^{8}$

\subsection{Atomic force microscope (AFM) experiments}

AFM experiments were performed using a NanoWizard Ultra Speed AFM (JPK Instruments, Germany) to investigate the assembly behaviors of 4-formylphenyl $\beta$-Dglucopyranoside. The aqueous solution of 4-formylphenyl $\beta$-D-glucopyranoside (5 $\mathrm{mM}$ ), as well as a mixed aqueous solution of 4-formylphenyl $\beta$-D-glucopyranoside (5 $\mathrm{mM})$ and Neu5Ac $(5 \mathrm{mM})$ were prepared precisely in advance. Then, two pieces of freshly cleaved micas were immersed in the above two solutions for 1 hour, respectively, allowing the self-assembled compounds to deposit on the mica surface. ${ }^{9}$ Then the mica with the self-assembled patterns on surface was imaged with AFM.

\subsection{X-ray diffraction (XRD) experiments}

4-Formylphenyl $\beta$-D-glucopyranoside was dissolved in water completely and then freeze-dried to a dry powder. The obtained dry powder $(30 \mathrm{mg})$ was filled in the measurement cell of XRD instrument. Then the XRD pattern was recorded in the range of $2 \theta=5 \sim 30^{\circ}$ at a scan rate of $0.05 \%$. In addition, the XRD pattern of the newly born 4-formylphenyl $\beta$-D-glucopyranoside that was collected from the hydrolysis products mixture was also recorded with the same method.

\subsection{Epic aggregation assay}

The aggregation assay was conducted to study the self-assembly behavior of 4formylphenyl $\beta$-D-glucopyranoside on the surface of a biosensor using the Label-free Corning ${ }^{\circledR}$ Epic ${ }^{\circledR}$ system. An Epic 384-Well Uncoated Cell Assay Microplate was 
used for detecting aggregation formation. Prior to measurements, the compound 4[(phenethylimino)methyl]phenyl D-glucopyranoside was dissolved into water to prepare a series of solutions with different concentrations. A set of microplates were first soaked in $30 \mu \mathrm{L}$ water (soaking buffer) and temperature-equilibrated in the Epic reader for at least 1 hour. After a baseline measurement was taken for $2 \mathrm{~min}$, a series of compound solutions with a volume of $10 \mu \mathrm{L}$ were added into microplates with 30 $\mu \mathrm{L}$ water (1:4 dilutions). Following compound addition, the 384-well microplate was returned immediately to the Epic reader and signal changes were recorded as continuous time traces for at least $30 \mathrm{~min} .{ }^{10} \mathrm{Each}$ of the assays was performed at least three times with satisfactory reproducibility.

\subsection{Surface enhanced Raman spectroscopy (SERS) experiments}

Silver nitrate $\left(\mathrm{AgNO}_{3}, 36 \mathrm{mg}\right)$ was dissolved in $200 \mathrm{~mL}$ of distilled water, the solution was heated to boiling. Then, a solution of $1 \%$ sodium citrate $(10 \mathrm{~mL})$ was added. The mixture solution was kept on boiling for $40 \mathrm{~min}$. The silver nanoparticles (AgNPs) were obtained with a form of aqueous solution. ${ }^{11}$ Then, $5 \mu \mathrm{L}$ of 4mercaptophenylboric acid (MPBA, $1.0 \mathrm{mmol} \cdot \mathrm{L}^{-1}$ ) aqueous solution was added into 10 $\mathrm{mL}$ of AgNPs solution. The mixture was mixed on the rotator at low speed for 3 hours. Then the solution was centrifuged at $7000 \mathrm{rpm}$ for $5 \mathrm{~min}$ to remove the supernatant, and was further dispersed into water with equal volume. The MPBAmodified AgNPs was obtained.

Raman spectroscopy was carried out on a Renishaw InVia Raman. A 50× (N.A. $=$ 0.8) objective was used to focus a $532 \mathrm{~nm}$ laser on the solution of MPBA-modified AgNPs and to collect the scattered light from the sample surface. ${ }^{12}$ 4-MPBA modified AgNPs $(50 \mu \mathrm{L})$ was incubated in PEA-Neu5Ac complex aqueous solution $(10 \mathrm{mM}$, $10 \mu \mathrm{L})$ or PEA-Neu5Ac mixture aqueous solution $(10 \mathrm{mM}, 10 \mu \mathrm{L})$, respectively, for 1 hour. Then, SERS signal changes of the MPBA-modified AgNPs upon binding of the PEA-Neu5Ac complex or PEA-Neu5Ac mixture were recorded using the above 
method.

\section{Analysis of sialylated disaccharide triggered Schiff base hydrolysis.}

To better mimic the complicated SGs, Neu5Ac $\alpha(2-3)$ Gal $\beta M P$ glycoside (abbreviated as NGg, a sialylated disaccharide) was selected as a model glycan to validate our findings. The reaction between the Schiff base $\mathbf{A}$ and NGg was investigated through the same separation, NMR characterisation, and identification procedures described in the main text. The addition of NGg also triggered the hydrolysis of the Schiff base A. And a new component that corresponded to the PEANGg complex was found through conducting the HPLC separation. The structure of the component was characterized by ${ }^{13} \mathrm{C}$ NMR (Figure S17). Moreover, the observed chemical shift changes of the PEA-NGg complex were similar to those observed in the ${ }^{13} \mathrm{C}$ NMR spectrum of the PEA-Neu5Ac complex. The ${ }^{1} \mathrm{H}$ NMR (Figure S19) and ${ }^{1} \mathrm{H}-{ }^{13} \mathrm{C}$ COSY NMR spectra (Figure S18) provided further evidence. Combined with the quantum chemistry calculation, a possible structure of the PEA-NGg complex was presented, as shown in Figure S17. The binding model of PEA and NGg was found to be consistent with the PEA-Neu5Ac binding. And, the core structure still is the high-affinity binding of Neu5Ac with PEA that was produced by the hydrolysis of Schiff base A. 


\section{Supplementary Figures and Tables}
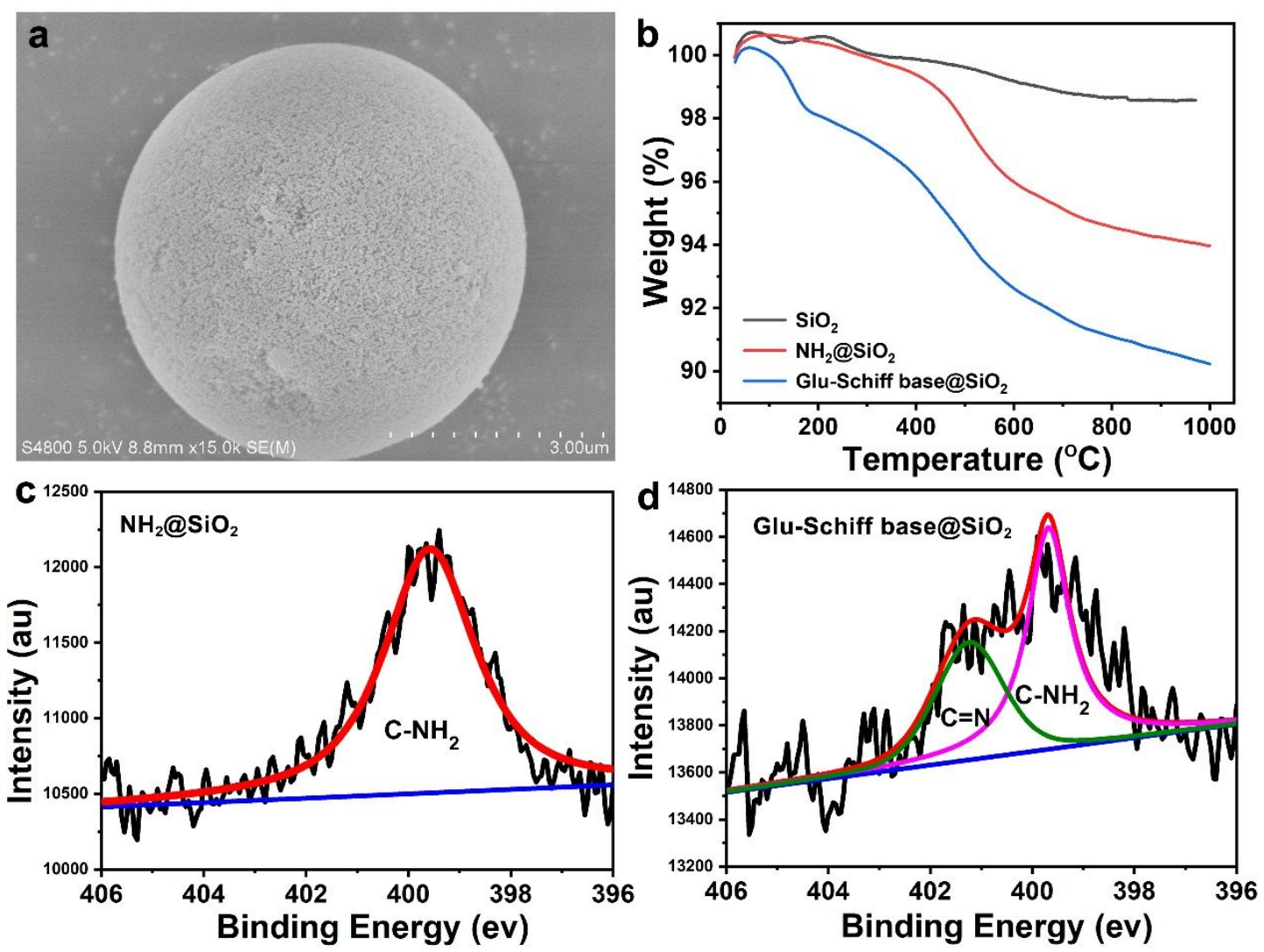

Figure S1. Characterization data of Glu-Schiff base@SiO 2 . (a) SEM image of Glu-Schiff base@ $\mathrm{SiO}_{2}$. (b) Thermo gravimetric analysis (TGA) curves of silica gel $\left(\mathrm{SiO}_{2}\right)$ (black), $\mathrm{NH}_{2} @ \mathrm{SiO}_{2}$ (red), Glu-Schiff base@ $\mathrm{SiO}_{2}$ (blue). Nitrogen element spectra of $\mathrm{NH}_{2} @ \mathrm{SiO}_{2}(\mathrm{c})$ and Glu-Schiff base@ $\mathrm{SiO}_{2}$ (d), respectively, obtained by XPS measurements. 

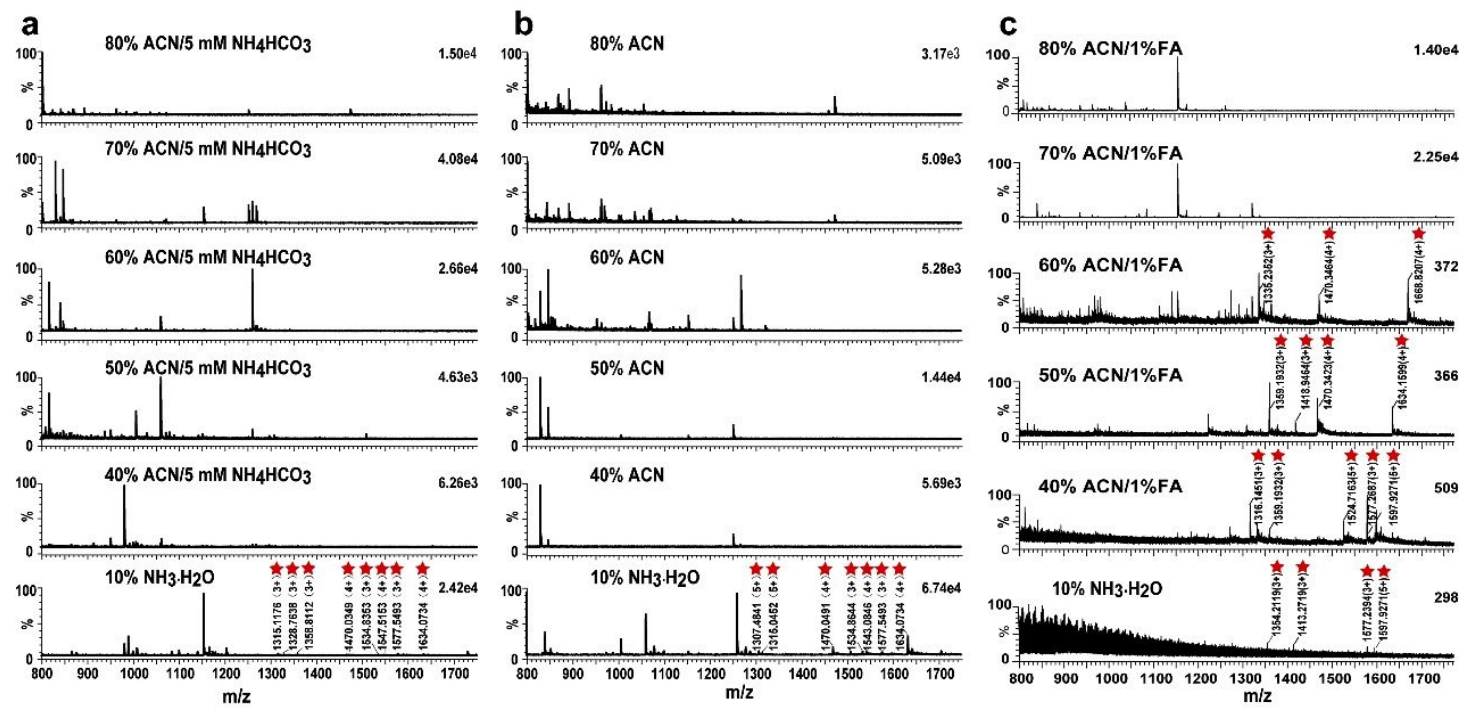

Figure S2. Mass spectra of fetuin digests eluted from Glu-Schiff base@ $\mathrm{SiO}_{2}$ with $\mathrm{ACN} / \mathrm{H}_{2} \mathrm{O}$ mixture with different $\mathrm{ACN}$ contents. In order to adjust the solution $\mathrm{pH}$ values, $5 \mathrm{mM} \mathrm{NH}_{4} \mathrm{HCO}_{3}$ $(\mathrm{pH} 8.3$, group a), ultrapure water ( $\mathrm{pH} 6.8$, group b) and $1 \%$ formic acid (FA, $\mathrm{pH} 2.9$, group c) were added to the mixtures, respectively. The MS signals belonging to glycopeptides are labelled with red pentacles, while the others are non-glycopeptides.

Discussion: At the beginning of the enrichment experiment, we had studied the retention of sialylated glycopeptides on the Glu-Schiff base@ $\mathrm{SiO}_{2}$ under different solution conditions, which varied in $\mathrm{ACN}$ content and the solution $\mathrm{pH}$. The tryptic digests of bovine fetuin were used as a model sample. After desalting of the fetuin digests with C18 SPE column, the fetuin digests were redissolved with $85 \% \mathrm{ACN}$ (aqueous solution, similarly hereafter), and loaded onto a series of Glu-Schiff base@ $\mathrm{SiO}_{2}$ packed microcolumns with identical sample amounts. The microcolumns were subsequently eluted with $80 \%$ ACN, $70 \% \mathrm{ACN}, 60 \% \mathrm{ACN}, 50 \% \mathrm{ACN}$, and $40 \% \mathrm{ACN}$ aqueous solution with $\mathrm{pH}$ of 6.8 (pure water), $\mathrm{pH}$ of $8.3\left(5 \mathrm{mM} \mathrm{NH}_{4} \mathrm{HCO}_{3}\right)$, and $\mathrm{pH}$ of $2.9(1 \%$ FA), respectively.

As shown in Figure S2a and S2b corresponding to the solution $\mathrm{pH} 8.3$ and $\mathrm{pH} 6.8$ conditions, our Glu-Schiff base material had strong retentions toward the sialylated glycopeptides (indicated by red pentacles), which could only be eluted by $10 \% \mathrm{NH}_{3} \cdot \mathrm{H}_{2} \mathrm{O}$. However, many nonglycopeptides signals could be observed in every fraction, which indicated that these interferences 
could not be removed sufficiently, resulting in unsatisfactory enrichment selectivity.

By comparison, under the acidic condition using 1\% FA ( $\mathrm{pH} 2.9$ ), most non-glycopeptides could be eluted by using $80 \%$ and $70 \% \mathrm{ACN} / \mathrm{H}_{2} \mathrm{O}$ containing $1 \% \mathrm{FA}$ (Figure $\mathrm{S} 2 \mathrm{c}$ ), the remove of interference would largely facilitate the identification of the glycopeptides. Owing to the competitive hydrolysis reaction induced by the acidic environment, the retention of the sialylated glycopeptides became a little weak compared with the neutral condition, a part of the glycopeptides were eluted by $40-60 \%$ ACN/1\%FA, while there were still some glycopeptides adsorbed on the material surface firmly, which were eluted only by $10 \% \mathrm{NH}_{3} \cdot \mathrm{H}_{2} \mathrm{O}$. Based on this knowledge, an optimum enrichment method was built, $85 \% \mathrm{ACN} / 1 \% \mathrm{FA}, 80 \% \mathrm{ACN} / 1 \% \mathrm{FA}$ and $10 \% \mathrm{NH}_{3} \cdot \mathrm{H}_{2} \mathrm{O}$ were chosen as the loading, washing and elution solutions, respectively.

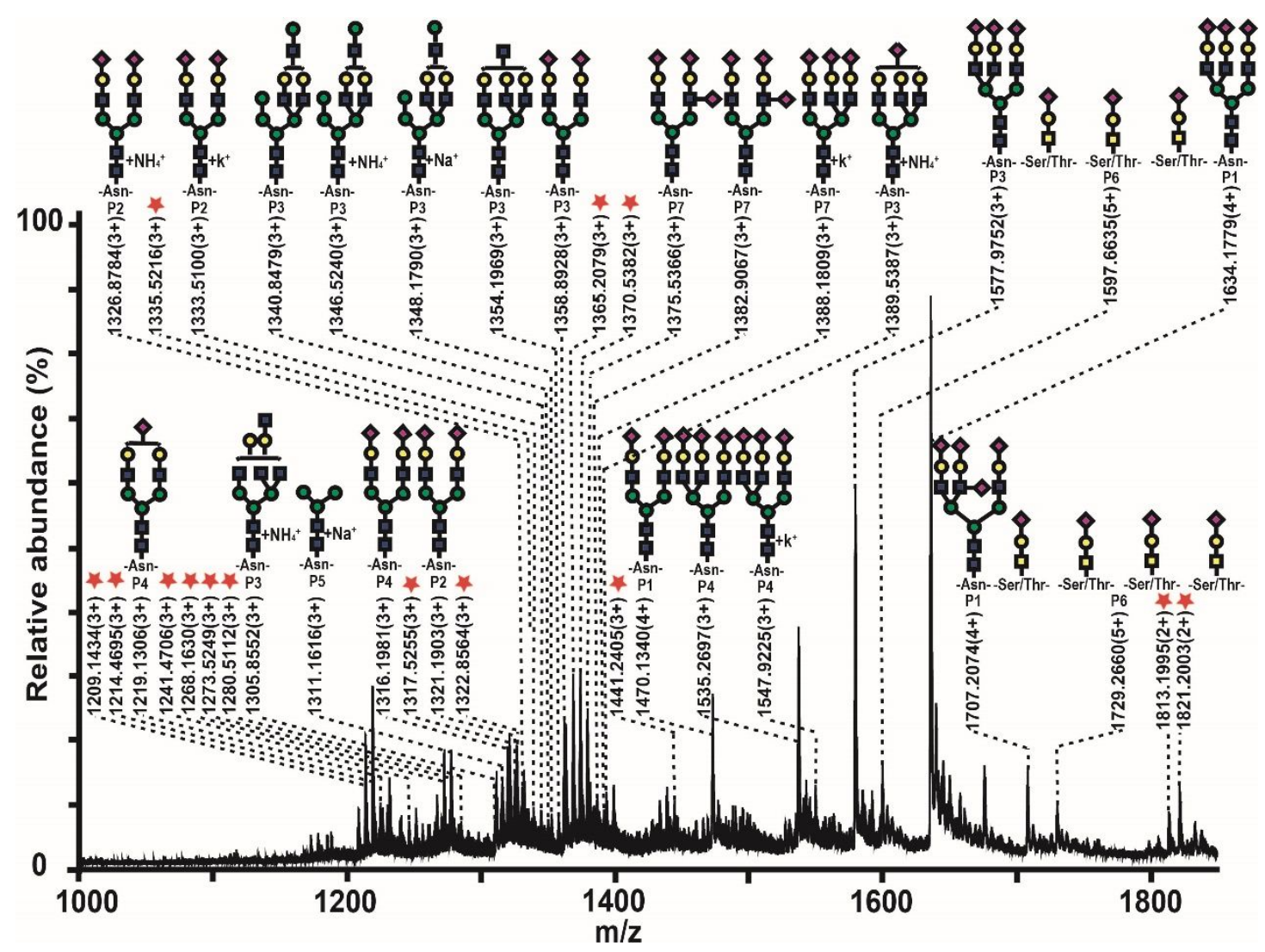

Figure S3. Mass spectrum of glycopeptides enriched with Glu-Schiff base@ $\mathrm{SiO}_{2}$ from the tryptic digestion of fetuin mixed with bovine serum albumin (BSA) interference at a molar ratio of 1:200. Glycopeptides are marked with red stars or their glycan structures : blue m: GlcNAc; green $\bullet$ :mannose; yellow $\bullet$ : galactose; purple $\bullet$ : Neu5Ac. 

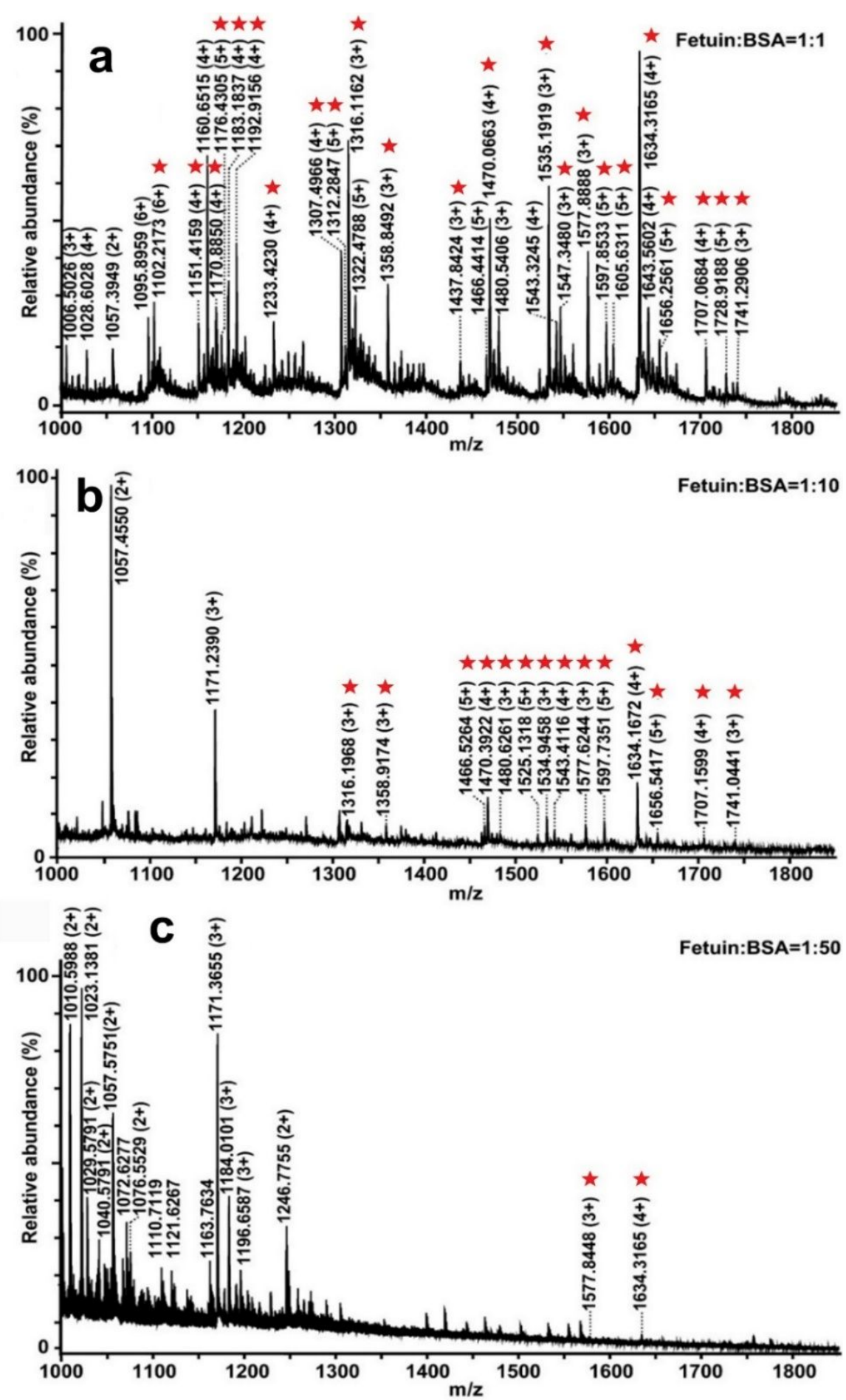

Figure S4. Mass spectra of glycopeptides enriched by ZIC-HILIC material from the tryptic digestion of fetuin mixed with different folds of BSA. Fetuin:BSA=1:1 (a); fetuin:BSA=1:10 (b); fetuin:BSA=1:50 (c). Glycopeptides are labelled with red pentacles. Non-modified peptides are only marked with their $\mathrm{m} / \mathrm{z}$ values. These data clearly indicated that the ZIC-HILIC material could not resist the interference of 50-fold BSA, demonstrating its poor enrichment selectivity. 

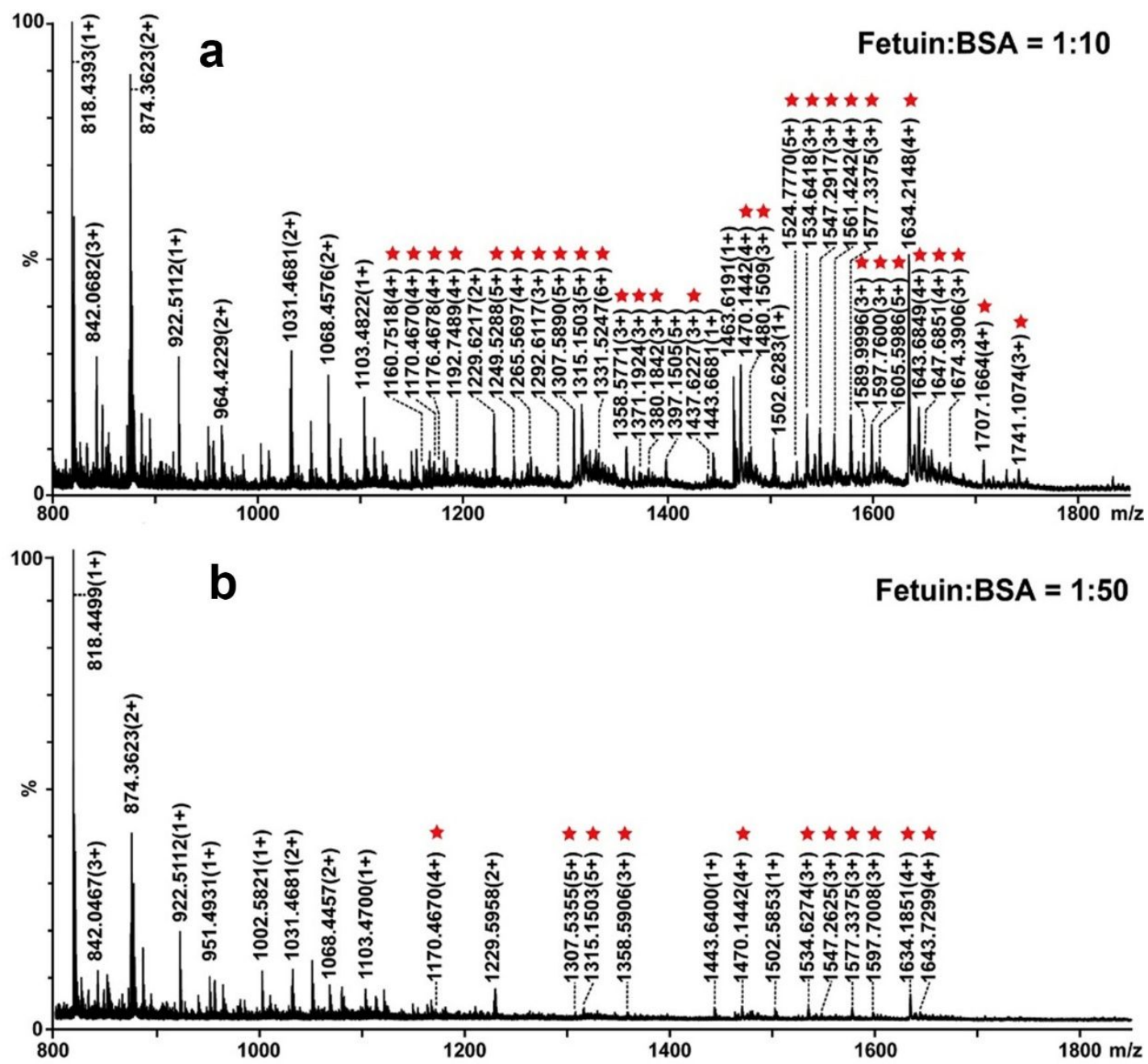

Figure S5. Mass spectra of glycopeptides enriched by Sepharose from the tryptic digests of fetuin mixed with 10-fold (a) or 50-fold (b) BSA. Non-modified peptides are only marked with their $\mathrm{m} / \mathrm{z}$ values and glycopeptides are marked with red pentacles. As one of the widely used commercial materials applied in glycoproteomics, Sepharose demonstrated unsatisfied selectivity towards glycopeptides, which did not work well when the BSA interference level was higher than 50-fold fetuin. 


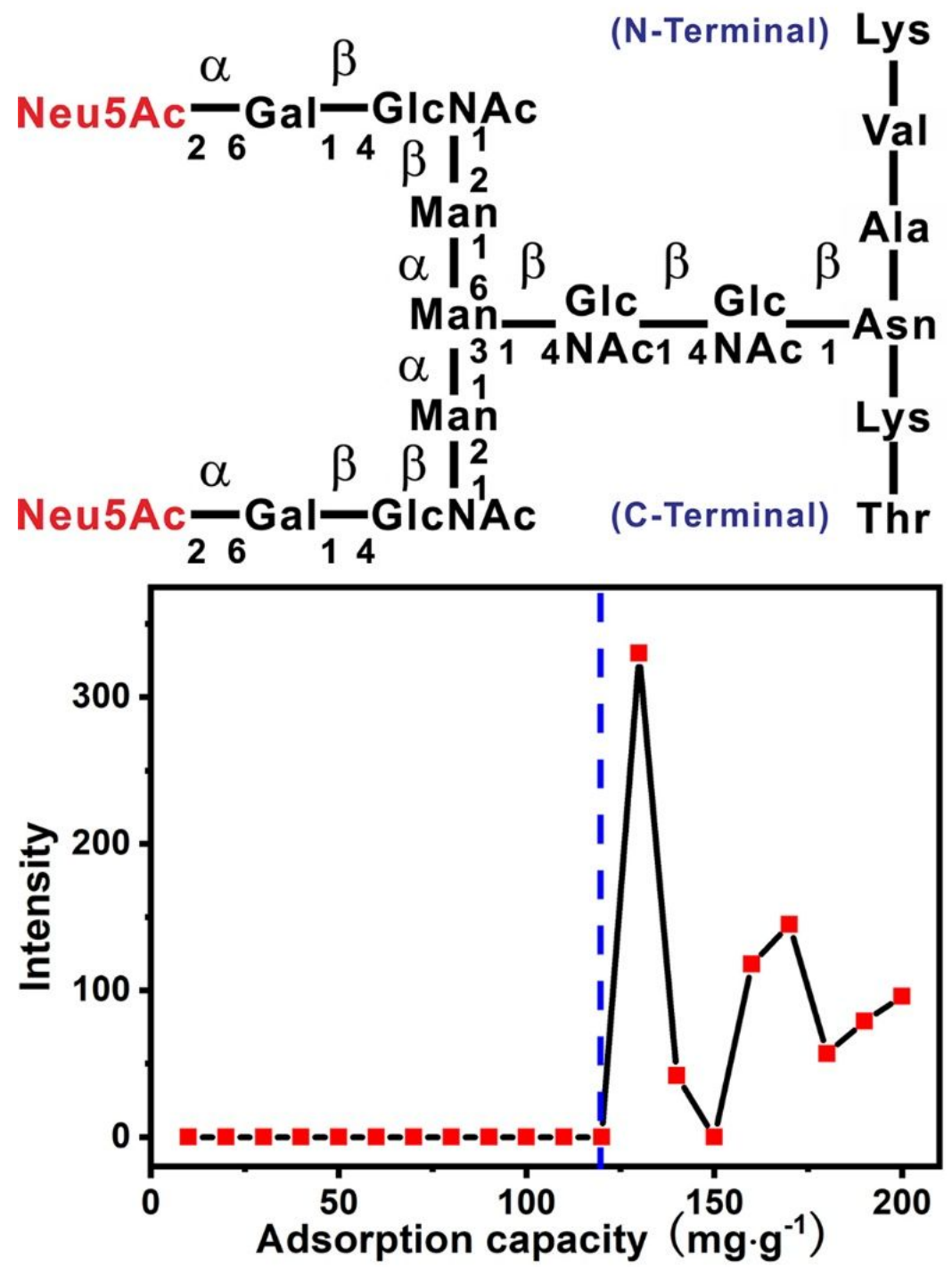

Figure S6. Chemical composition and peptide sequence of a standard sialylated glycopeptide (CAS No. 189035-43-6) and its adsorption capacity on Glu-Schiff base@ $\mathrm{SiO}_{2}$, glycopeptide loading conditions: $75 \% \mathrm{CH}_{3} \mathrm{CN} / 0.1 \% \mathrm{TFA}\left(0.05 \mu \mathrm{g} \cdot \mu \mathrm{L}^{-1}\right)$. 
a

$20 \pm 1^{\circ}$

Glu-Schiff base@SiO2

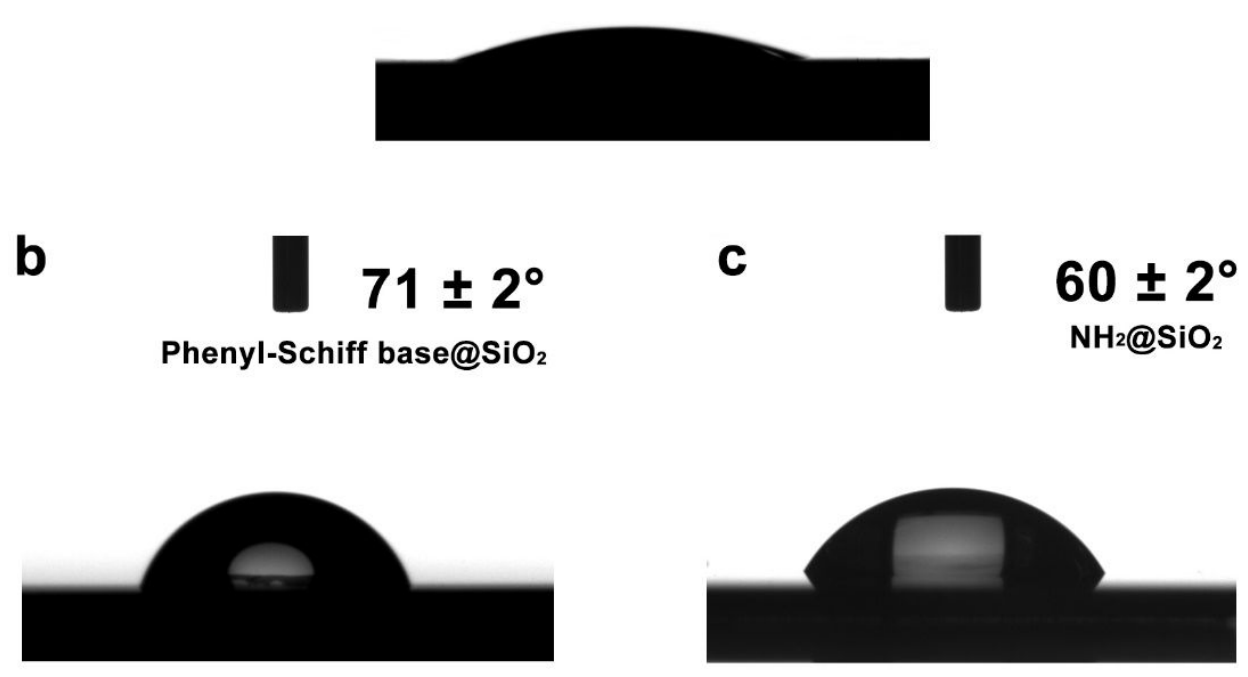

Figure S7. Water droplet profiles and the corresponding contact angles on Glu-Schiff basemodified 2D silica surface that equal to Glu-Schiff base@SiO 2 (a), Phenyl-Schiff base-modified 2D silica surface that equal to Phenyl-Schiff base@ $\mathrm{SiO}_{2}(\mathrm{~b})$, and $\mathrm{NH}_{2}$-modified 2D silica surface that equal to $\mathrm{NH}_{2} @ \mathrm{SiO}_{2}$ (c). Substantially lower contact angle indicated that Glu-Schiff base modified silica surface was more hydrophilic than Phenyl-Schiff base or amino modified surface. 


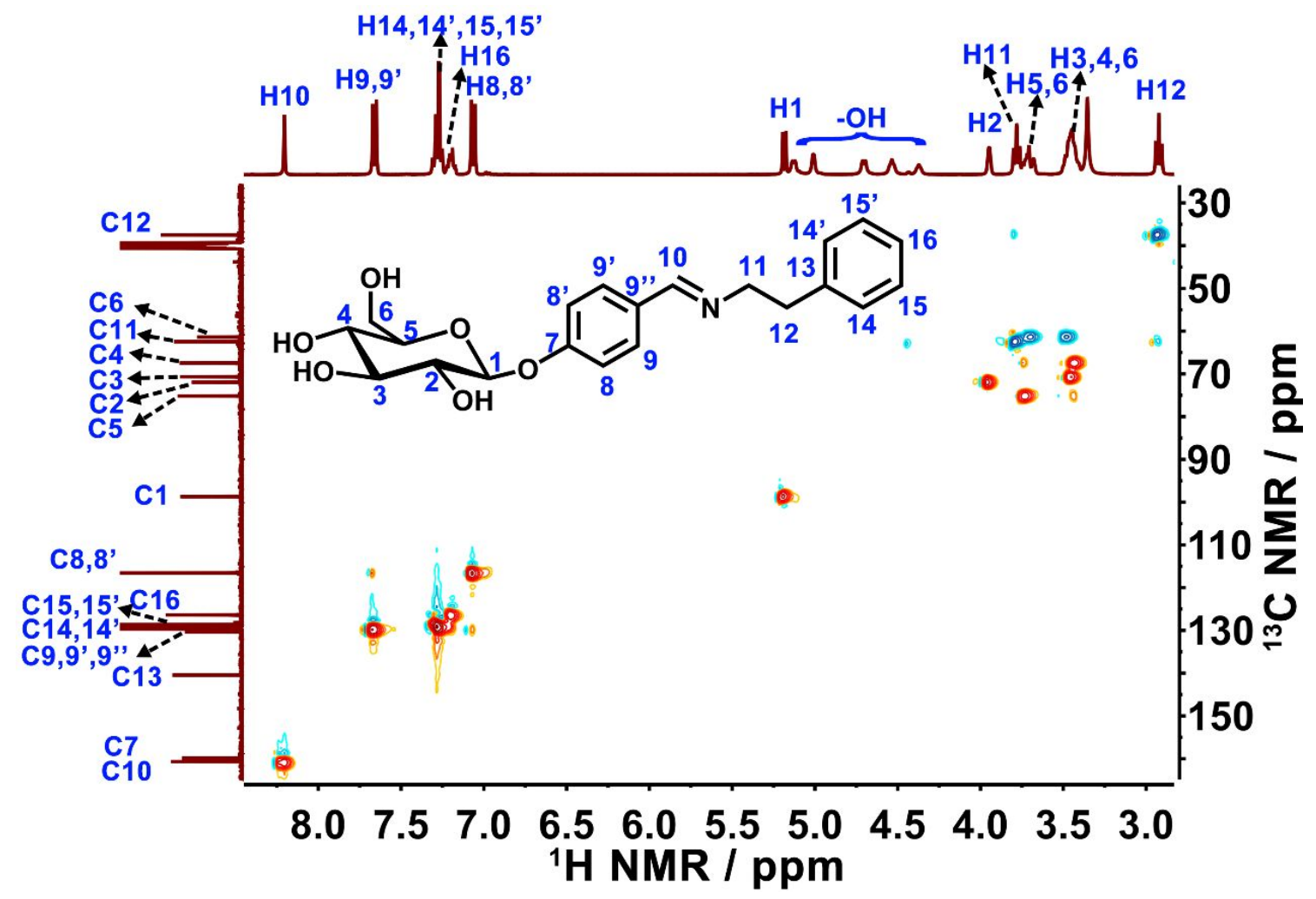

Figure S8. ${ }^{1} \mathrm{H}-{ }^{13} \mathrm{C}$ COSY NMR spectrum of of 4-[(phenethylimino) methyl]phenyl Dglucopyranoside (Schiff base A) in DMSO- $d_{6}$ at $20^{\circ} \mathrm{C}$, concentration: $40 \mathrm{mg} \cdot \mathrm{mL}^{-1}$. 


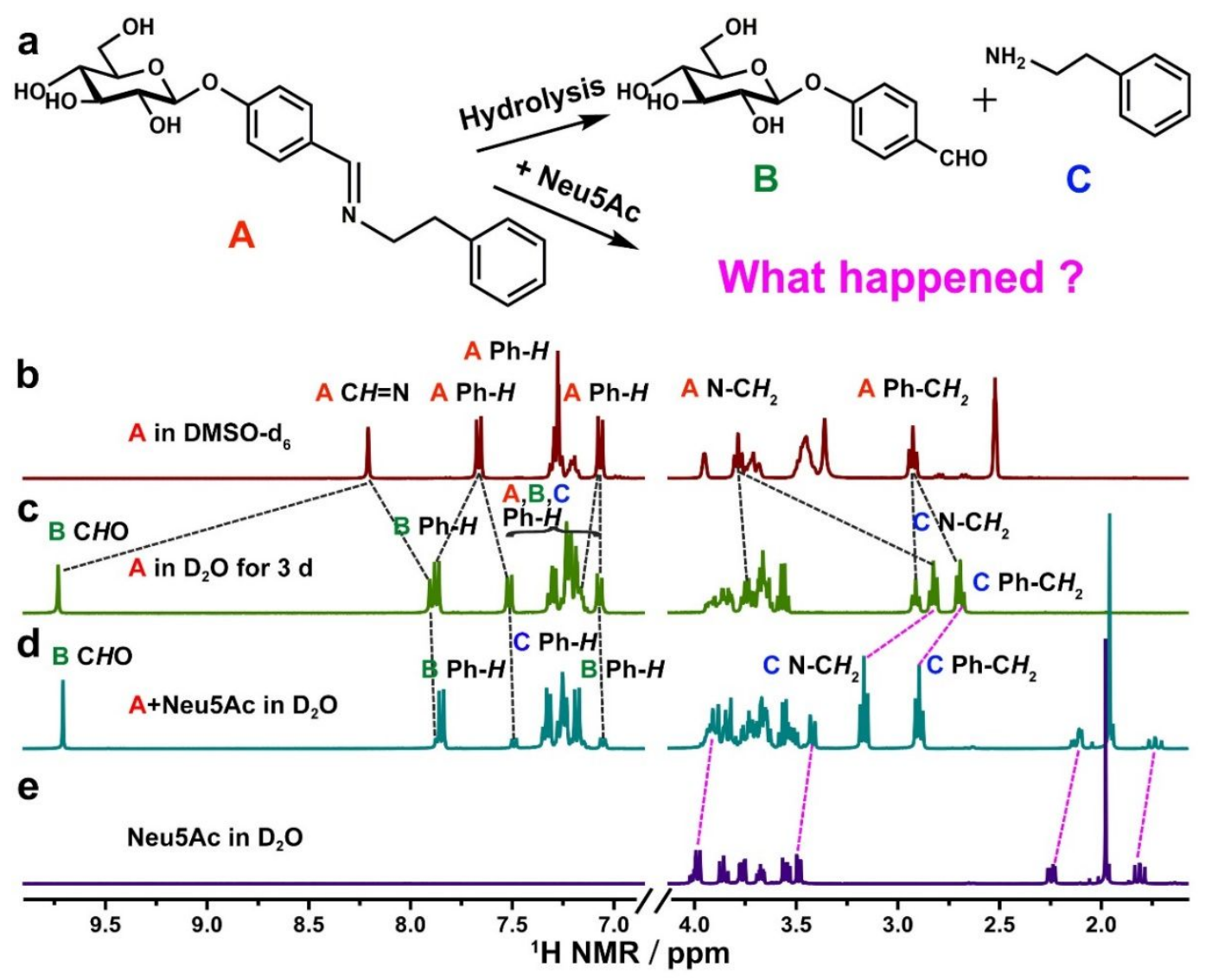

Figure S9. (a) Illustration of the hydrolysis reaction of Schiff base $\mathbf{A}$ and the core topic of this study-that what happens when Neu5Ac is added into the Schiff base A solution? (b-e) ${ }^{1} \mathrm{H}$ NMR spectra of Schiff base A in DMSO- $d_{6}$ (b), Schiff base $\mathbf{A}$ in $\mathrm{D}_{2} \mathrm{O}$ (c), a mixture of Schiff base $\mathbf{A}$ with equimolar Neu5Ac in $\mathrm{D}_{2} \mathrm{O}(\mathrm{d})$, and individual Neu5Ac in $\mathrm{D}_{2} \mathrm{O}(\mathrm{e})$. Chemical shift changes are indicated by black or violet dashed lines.

Discussion: Schiff base A was stable in DMSO- $d_{6}\left({ }^{1} \mathrm{H},{ }^{1} \mathrm{H}-{ }^{13} \mathrm{C}\right.$ COSY NMR spectrum as shown in Figure S8 and 9b). However, Schiff base A hydrolysed slowly into phenylethanamine (PEA) and 4-formylphenyl $\beta$-D-glucopyranoside (abbreviated as $\mathbf{B}$ ) in $\mathrm{D}_{2} \mathrm{O}$ and achieved a hydrolysis equilibrium about 3 days. The final hydrolysis ratio was approximately $57 \%$ (Figure S9c). When an equimolar Neu5Ac was added, the Schiff base A hydrolyzed rapidly (Figure S9d). Moreover, the four pairs of characteristic peaks of $\mathrm{C}-\mathrm{H}$ protons of Neu5Ac presented clear up-field shifts in ${ }^{1} \mathrm{H}$ NMR spectra (Figure S9). Remarkable changes in ${ }^{1} \mathrm{H}$ NMR spectra clearly indicated that not only a Neu5Ac-triggered Schiff base hydrolysis reaction occurred, but also an additional chemical reaction or an ultra-strong interaction between Neu5Ac and the hydrolysates might exist. 

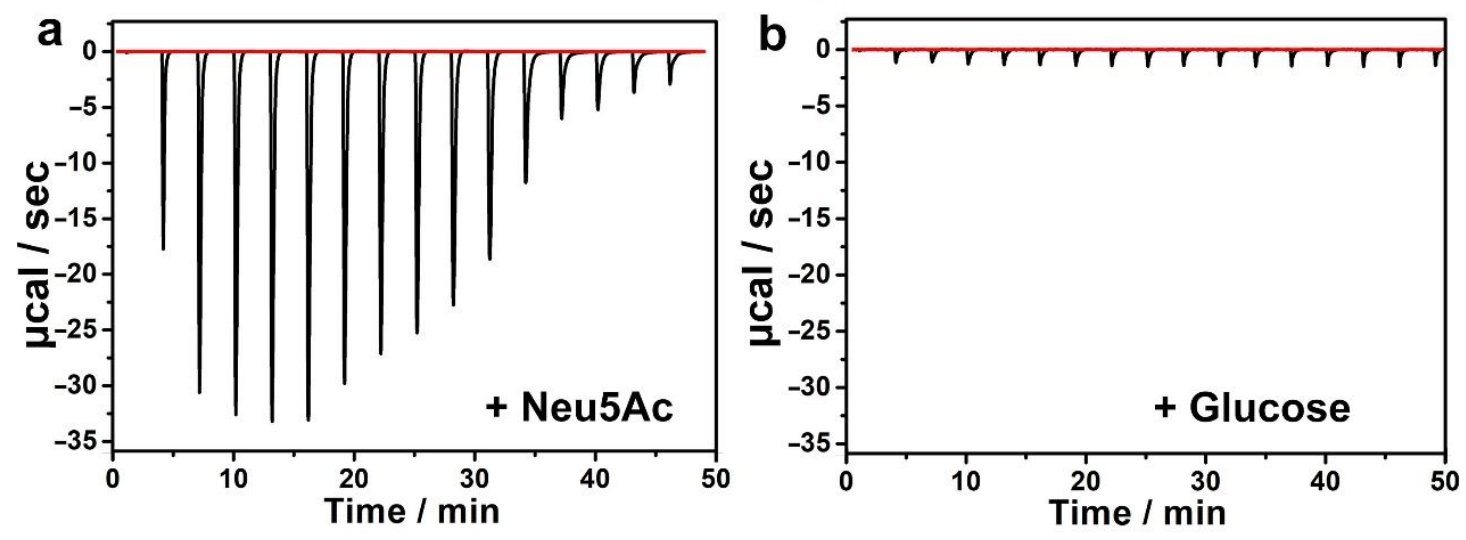

Figure S10. ITC data of Schiff base A (2 mM) titrated by Neu5Ac (a, $20 \mathrm{mM})$ or glucose (b, 20 $\mathrm{mM}$ ) in $\mathrm{H}_{2} \mathrm{O}$ at $25^{\circ} \mathrm{C}$. The intensive heat release in (a) revealed that the chemical reaction occurred due to the addition of Neu5Ac. Strong exothermic response $\left(33 \mu \mathrm{cal} \cdot \mathrm{s}^{-1}\right)$ was observed as the gradual titration of Neu5Ac into the Schiff base A aqueous solution through ITC (a). However, the titration of glucose to the Schiff base A aqueous solution only produced a very little heat of lower than $1 \mu \mathrm{cal} \cdot \mathrm{s}^{-1}(\mathrm{~b})$. Thus, the strong exothermic response should be attributed to the combined effect of triggered Schiff base hydrolysis and the subsequent chemical reactions or strong interactions between Neu5Ac and the hydrolysates. 

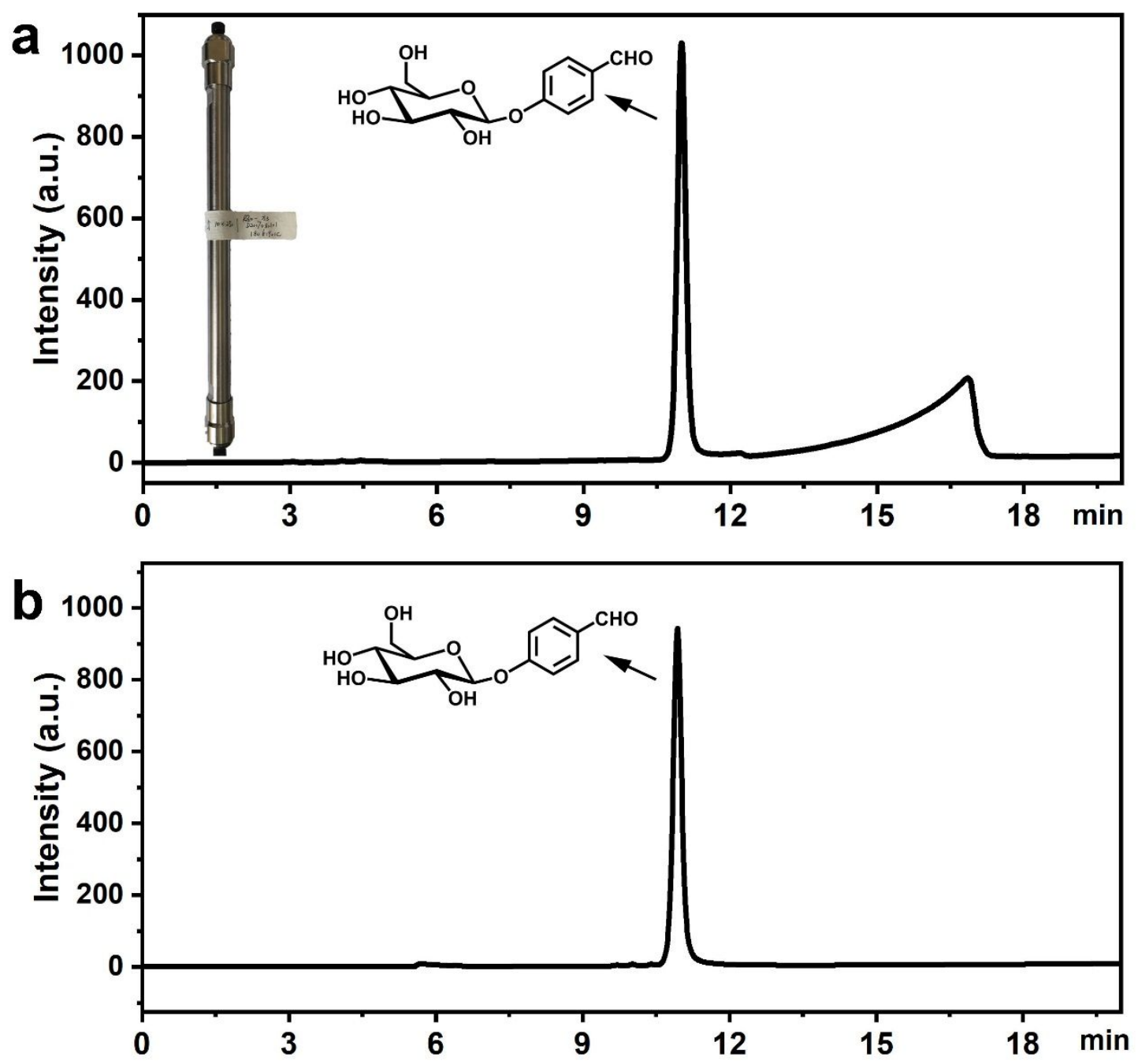

Figure S11. High performance liquid chromatography (HPLC) diagram for separating the hydrolysis products of the Schiff base A upon interaction with Neu5Ac (a), and pure 4formylphenyl $\beta$-D-glucopyranoside (b). In this separation, a home-made Click TE-Cys semipreparative liquid chromatography column (as shown in the inset of a) was used and the same gradient elution method was applied: a linear gradient of $90 \%-50 \%$ acetonitrile over 20 min at a flow rate of $3 \mathrm{~mL} \cdot \mathrm{min}^{-1}$. These data clearly demonstrated that the sharp peak at $11 \mathrm{~min}$ was ascribed to the hydrolysis product 4-formylphenyl $\beta$-D-glucopyranoside and a new product with retention at $17 \mathrm{~min}$ was generated. 

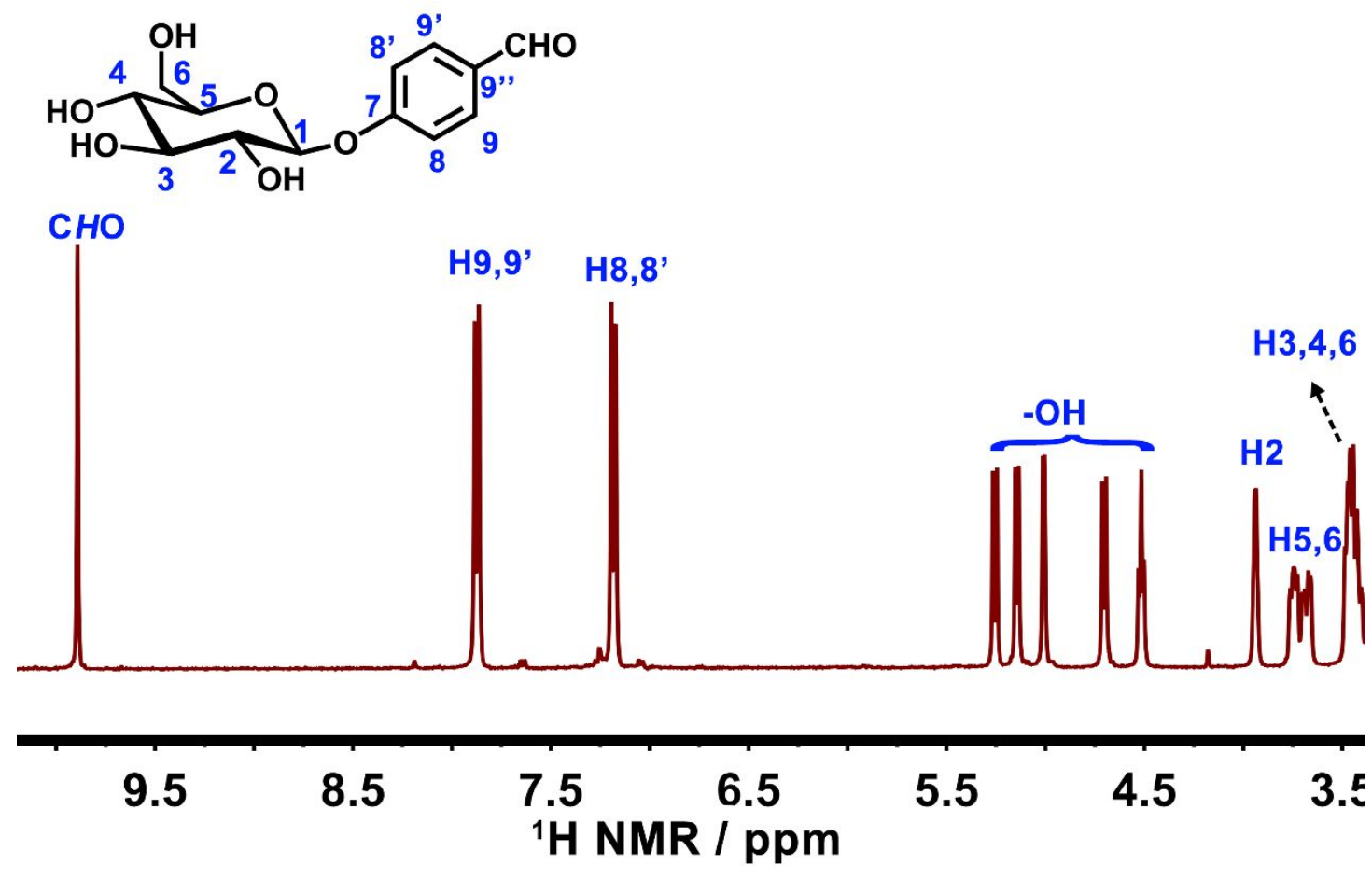

Figure S12. ${ }^{1} \mathrm{H}$ NMR spectrum of the compound with the sharp peak at 11 min in HPLC diagram, which was isolated and collected by the home-made Click TE-Cys semi-preparative liquid chromatography column, in DMSO- $d_{6}$ at $20^{\circ} \mathrm{C}$. This data further proved that the sharp peak at 11 min was ascribed to 4-formylphenyl $\beta$-D-glucopyranoside. 


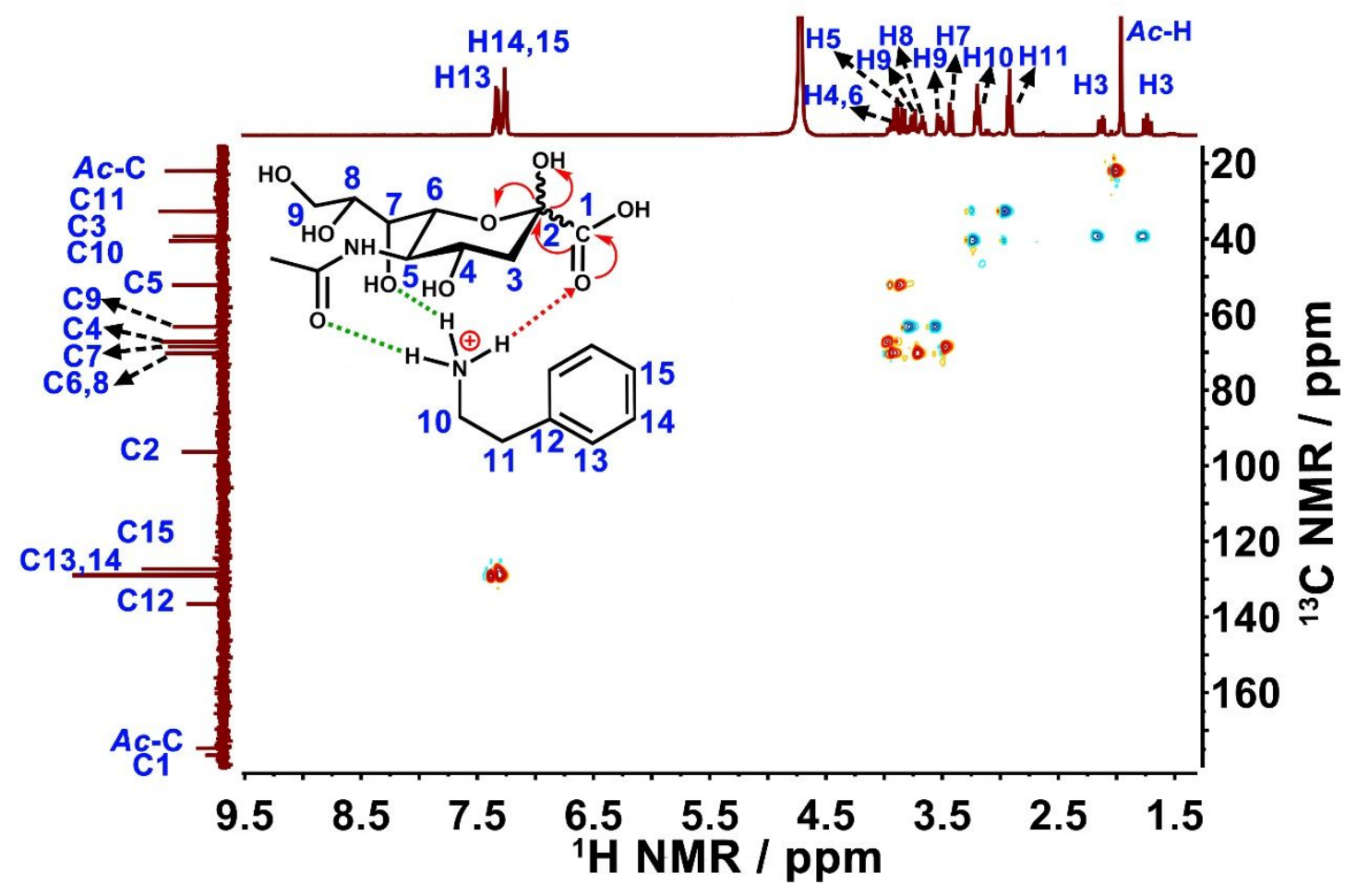

Figure S13. ${ }^{1} \mathrm{H}-{ }^{13} \mathrm{C}$ COSY NMR spectrum of PEA-Neu5Ac complex in $\mathrm{D}_{2} \mathrm{O}$ at $20{ }^{\circ} \mathrm{C}$, concentration: $40 \mathrm{mg} \cdot \mathrm{mL}^{-1}$. 


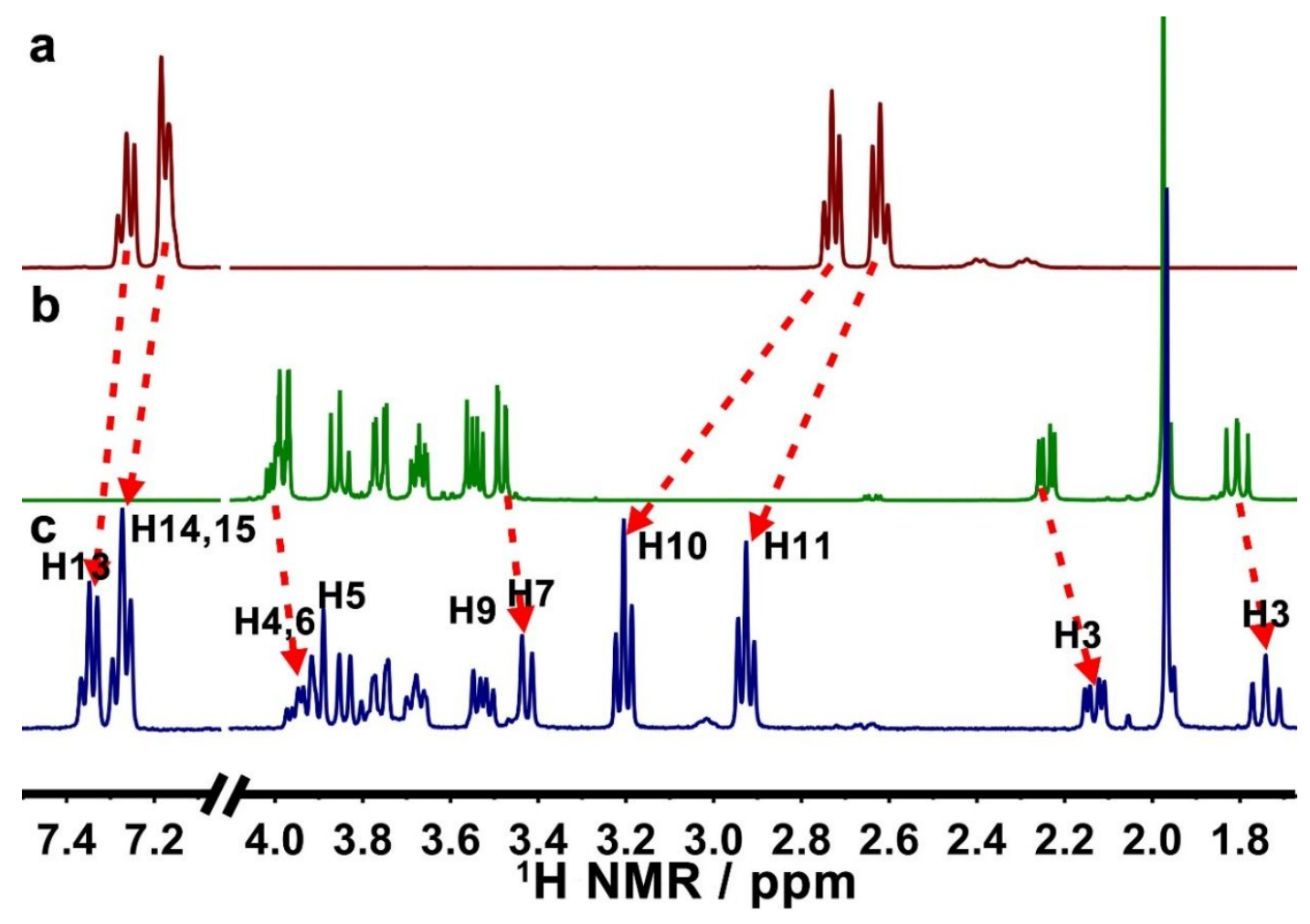

Figure S14. ${ }^{1} \mathrm{H}$ NMR spectra of PEA (a), Neu5Ac (b), and PEA-Neu5Ac complex (c) in $\mathrm{D}_{2} \mathrm{O}$ at $20{ }^{\circ} \mathrm{C}$, concentrations: $10 \mathrm{mg} \cdot \mathrm{mL}^{-1}$. Chemical shift changes are indicated by red arrows. 


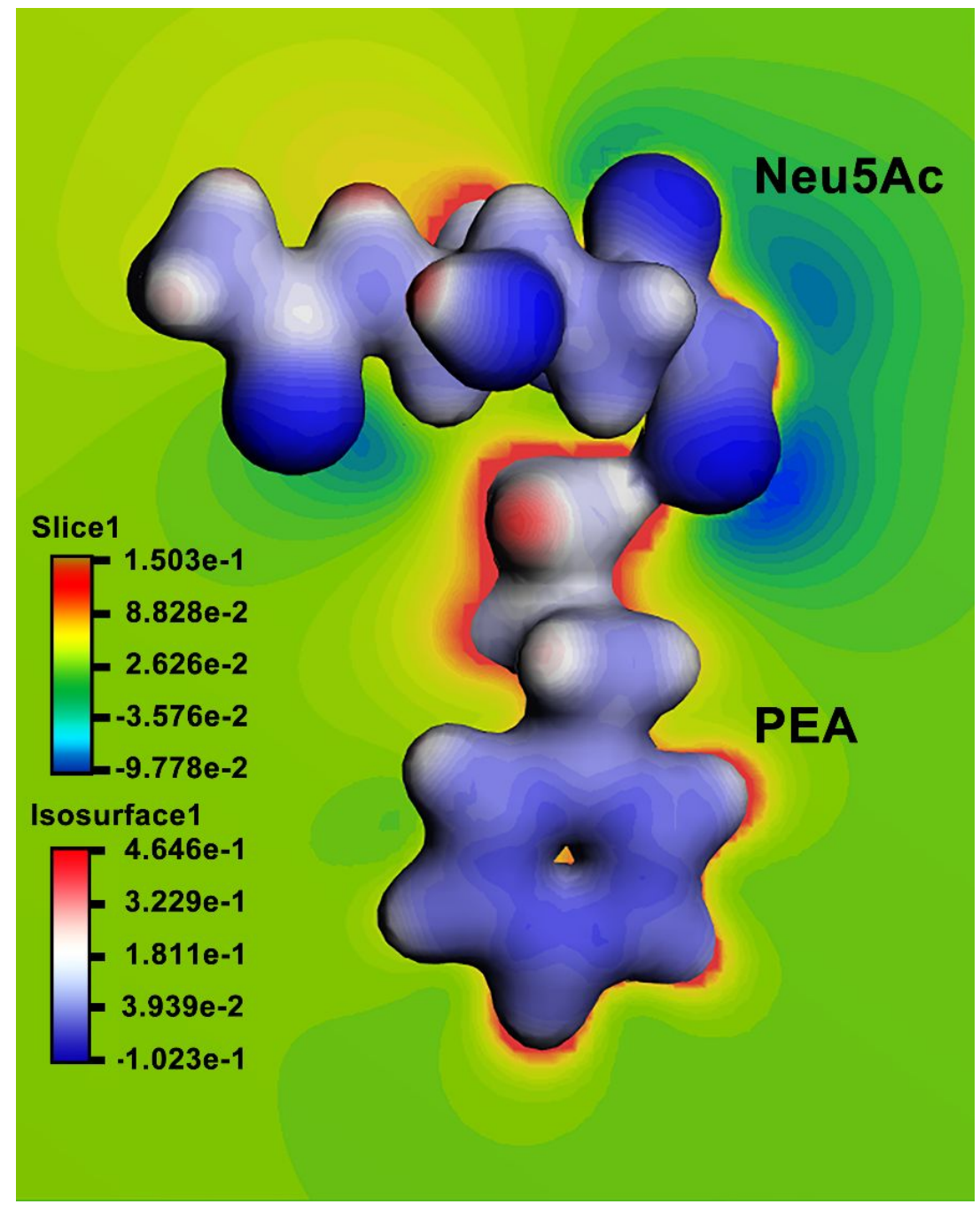

Figure S15. Density functional theory (DFT) was used to explain the formation of the Neu5AcPEA complex from the molecular perspective. The molecular electrostatic potential (ESP) obtained by DFT can qualitatively describe charge distribution and electrostatic interaction in the system. As shown in illustration, the bluer the color, the greater the amount of positive charge, and vice versa. The ESP map clearly shows that the complexation relies on a strong electrostatic interaction between the positively charged amine in PEA and the carboxylic acid in Neu5Ac. 

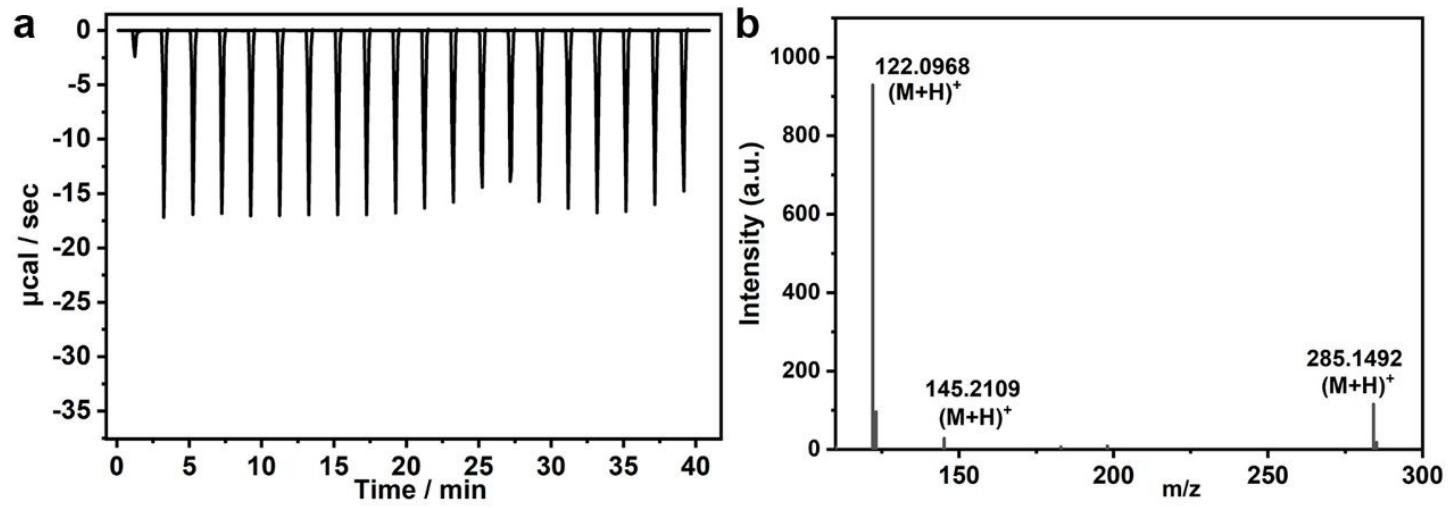

Figure S16. (a) ITC data of Schiff base A (2 mM) titrated by octanoic acid $(20 \mathrm{mM})$ in $\mathrm{H}_{2} \mathrm{O}$ at $25^{\circ} \mathrm{C}$. (b) Mass spectrum (MS) of the reaction products of the Schiff base hydrolysis in the presence of octanoic acid.

Discussion: Octanoic acid was chosen as an acidic alternative of Neu5Ac to perform the control experiments to disclose the acidic role of Neu5Ac in the Schiff base hydrolysis. In the ITC experiment, upon titration of octanoic acid into the Schiff base A solution, strong exothermic responses (over $15 \mu \mathrm{cal} \cdot \mathrm{s}^{-1}$ ) were also observed (Figure S16a), which were roughly comparable to that of the titration of Neu5Ac into the Schiff base A solution. This indicated that octanoic acid could also trigger the hydrolysis of the Schiff base A, accompanied with an obvious heat release.

Then, the hydrolysis products were analyzed through mass spectrometer. As shown in Figure S16b, the ion peaks at $\mathrm{m} / \mathrm{z} 285.1492,145.2109$, and 122.0968 were determined from the 4formylphenyl $\beta$-D-glucopyranoside (mw: 284.09), octanoic acid (mw: 144.02) and the PEA (mw: 121.1), respectively. No new ion peak that corresponded to a new complex between PEA and octanoic acid (mw: 265.12) was observed, suggesting that octanoic acid-triggered Schiff base hydrolysis did not generate the stable complex with the released PEA. This result indicated that the acidity of Neu5Ac played a key role in the hydrolysis, and formation of the PEA-Neu5Ac complex indeed relied on multiple interactions between the released PEA with multiple groups of Neu5Ac. 


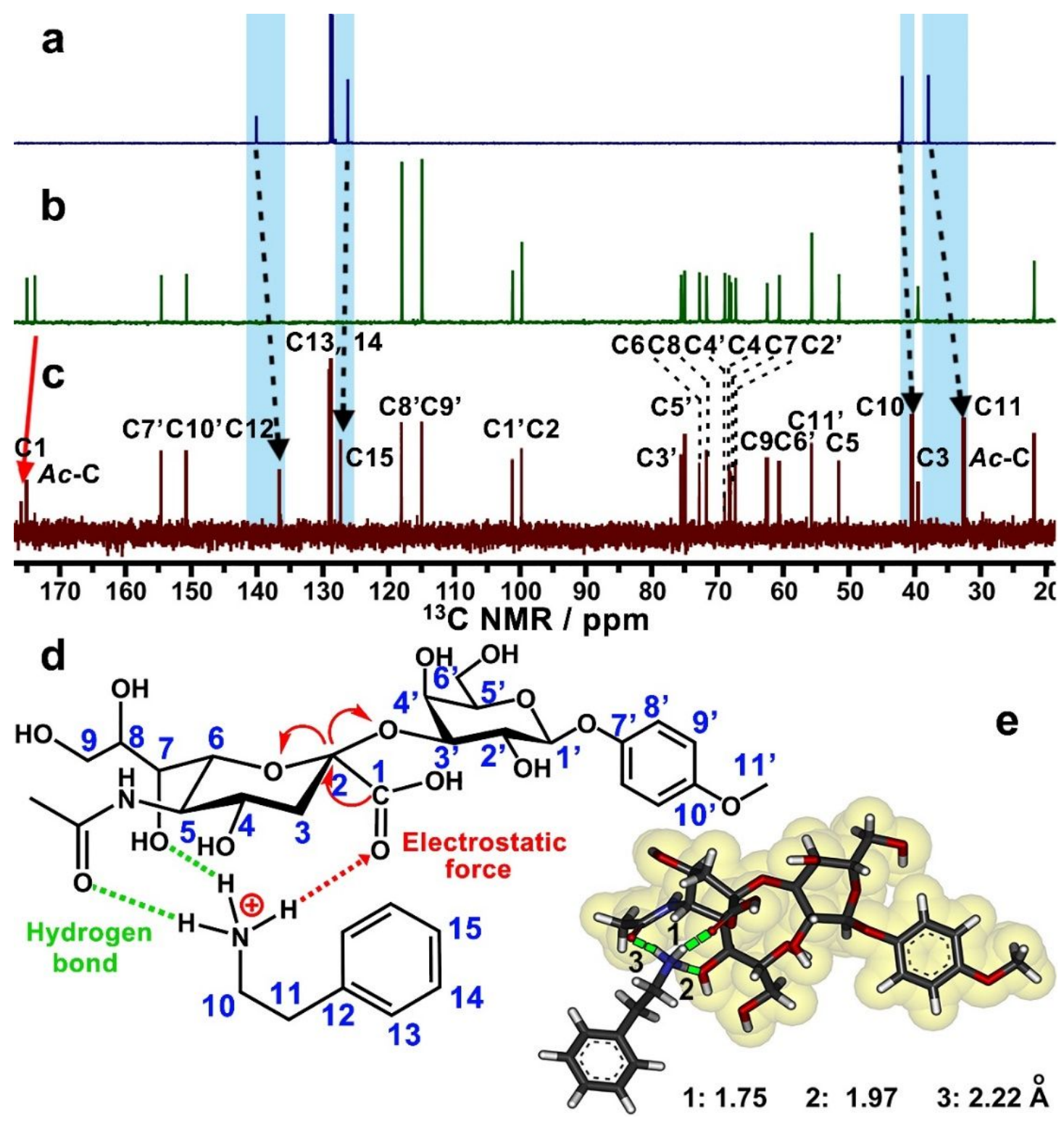

Figure S17. Characterization data of the PEA-Neu5Ac $\alpha(2-3)$ Gal $\beta M P$ complex. ${ }^{13} \mathrm{C}$ NMR spectra of PEA (a), Neu5Ac $\alpha(2-3)$ GalßMP glycoside (abbreviated as NGg) (b), and the PEA-Neu5Aca(23)GalßMP glycoside (abbreviated as PEA-NGg) complex (c) obtained from the Schiff base hydrolysis reaction, solvent: $\mathrm{D}_{2} \mathrm{O}$, concentrations: $40 \mathrm{mg} \cdot \mathrm{mL}^{-1}$. (d) A possible binding mode between NGg and PEA, and the chemical attribution of each $\mathrm{C}$ atom and $\mathrm{H}$ proton presented in the ${ }^{13} \mathrm{C}$ NMR spectra. (e) A possible binding model of the PEA-NGg complex that was obtained by quantum chemistry calculation (Gaussian, DFT at 6-311g level), in which water was set as a solvent parameter. 


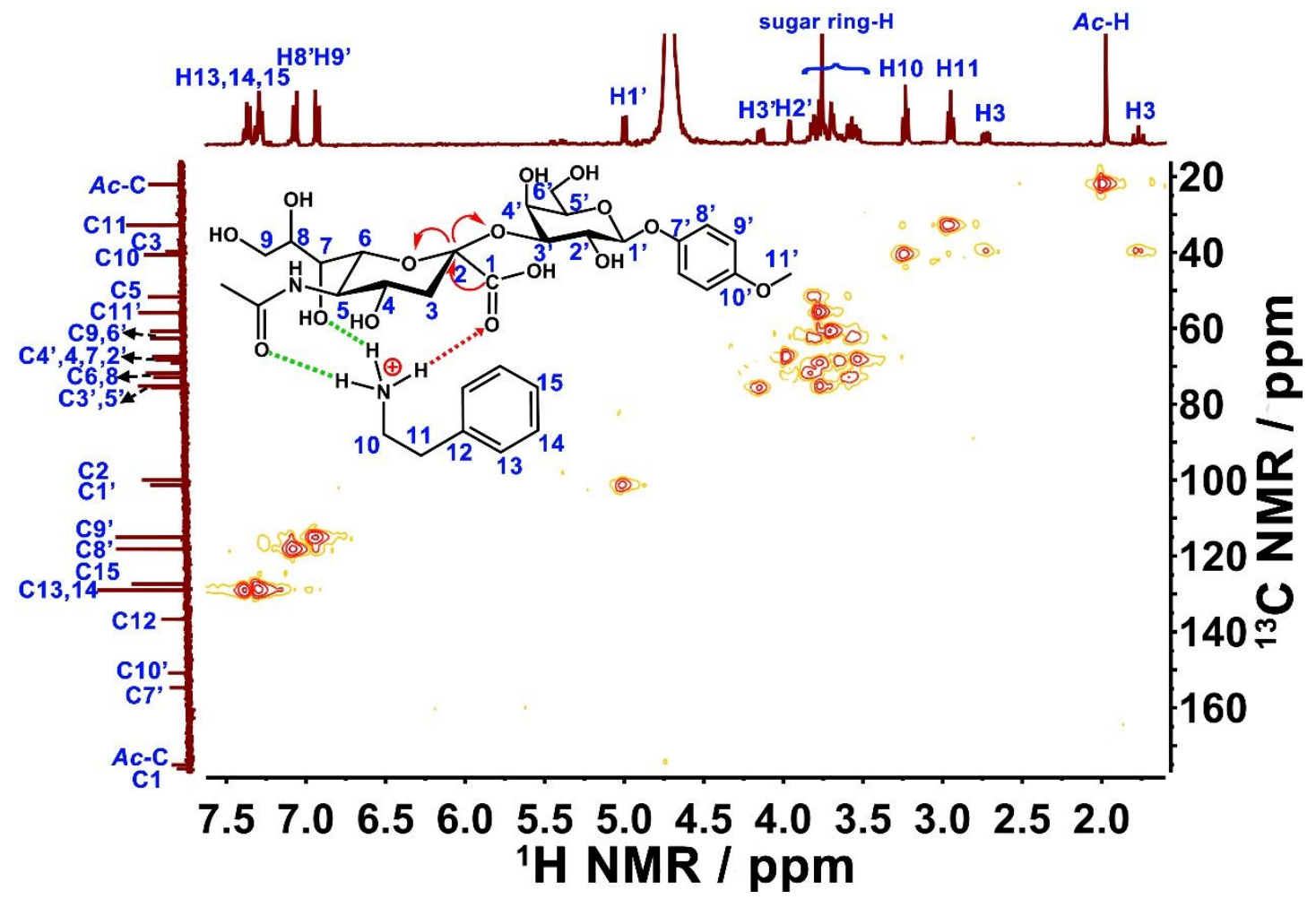

Figure S18. ${ }^{1} \mathrm{H}-{ }^{13} \mathrm{C}$ COSY NMR spectrum of PEA-NGg complex in DMSO- $d_{6}$ at $20{ }^{\circ} \mathrm{C}$, concentration: $40 \mathrm{mg} \cdot \mathrm{mL}^{-1}$. 


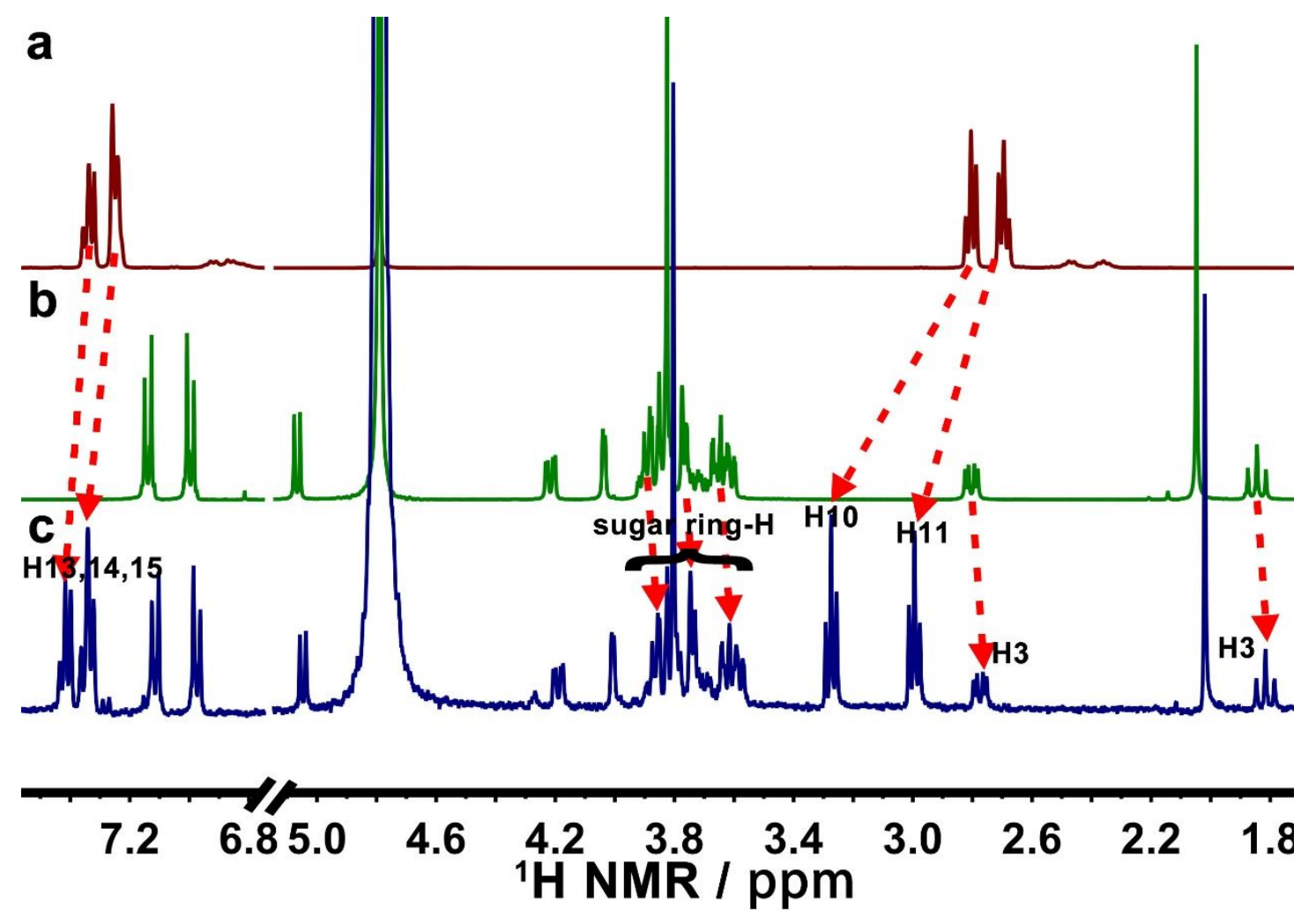

Figure S19. ${ }^{1} \mathrm{H}$ NMR spectra of PEA (a), Neu5Aca(2-3)GalßMP glycoside (NGg) (b) and PEANGg complex (c) in $\mathrm{D}_{2} \mathrm{O}$ at $20^{\circ} \mathrm{C}$, concentrations: $10 \mathrm{mg} \cdot \mathrm{mL}^{-1}$. Chemical shift changes are indicated by red arrows. 

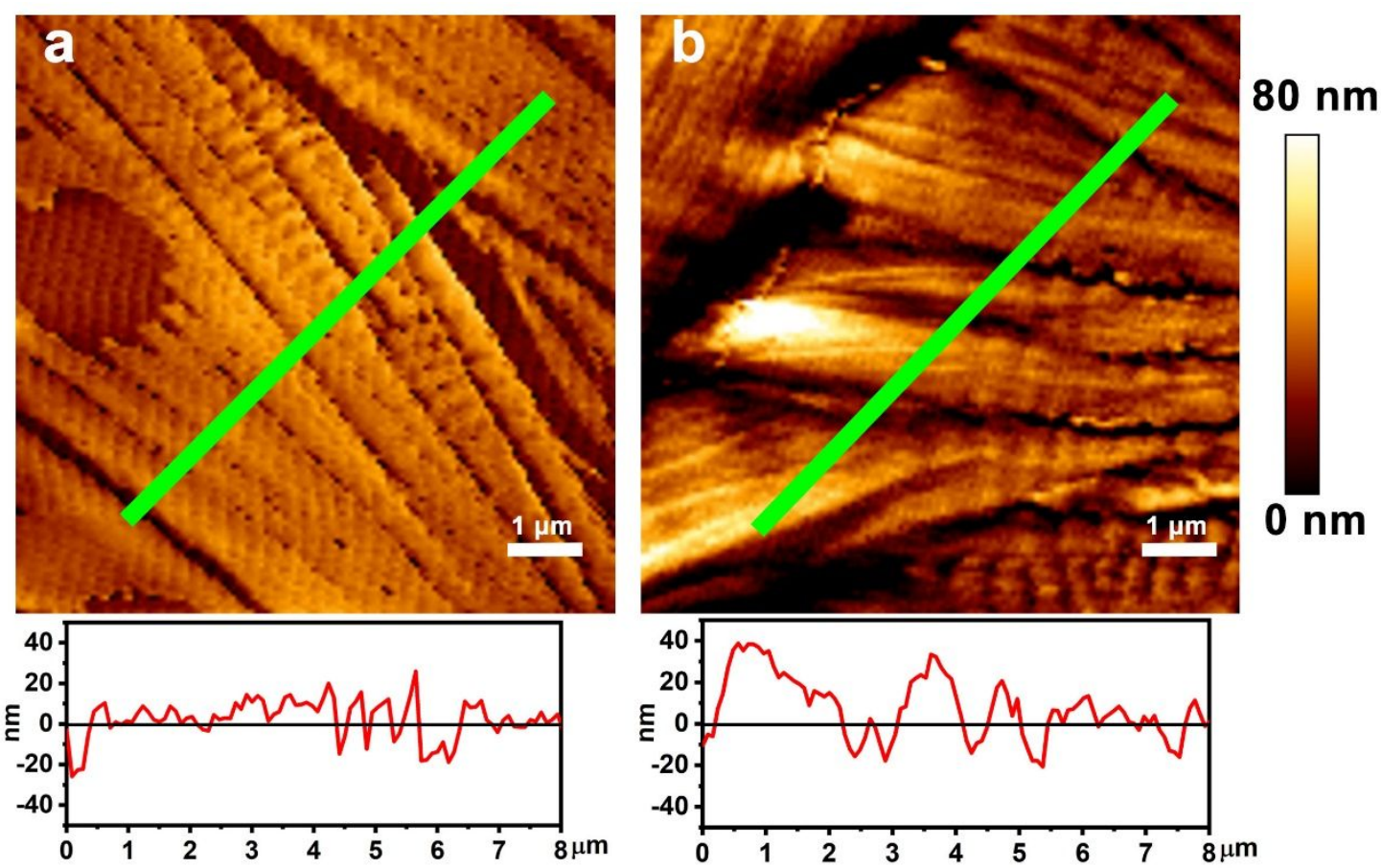

Figure S20. Large-scale AFM images of mica surface after being immersed in a hydrolysis reaction mixture of Schiff base A in the presence of Neu5Ac (a), or in a 4-formylphenyl $\beta$-Dglucopyranoside solution (b, $5 \mathrm{mM}$ ), respectively, and corresponding section profiles of the AFM images along the green lines. 


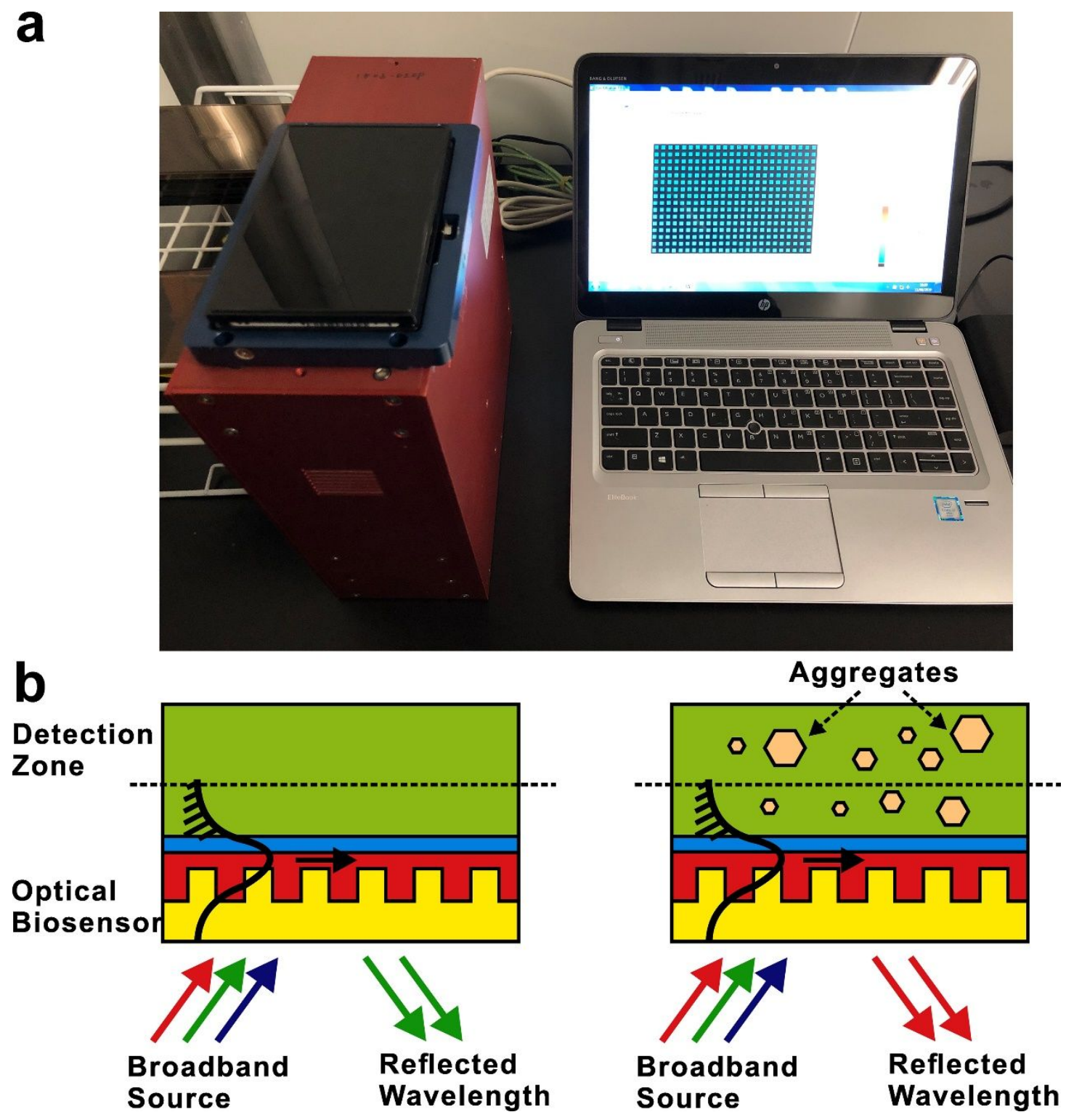

Figure S21. (a) Photo of the label-free Corning® Epic $₫$ system and its detection mechanism (b). Compound aggregation can be detected using a simple add and read assay format. The uncoated Epic microplates containing integrated optical sensors in each well are first soaked with assay buffer and a $15 \mathrm{~min}$ baseline measurement is taken to guarantee the stability of this system. Then the compounds are soluble in distilled water or in a $\mathrm{DMSO} / \mathrm{H}_{2} \mathrm{O}$ mixture. The compound aggregation formation at the surface of the biosensor is monitored by measuring the wavelength shift of reflected resonant light. This information and the schematic diagrams are obtained from the Corning Epic operation manual. 
a
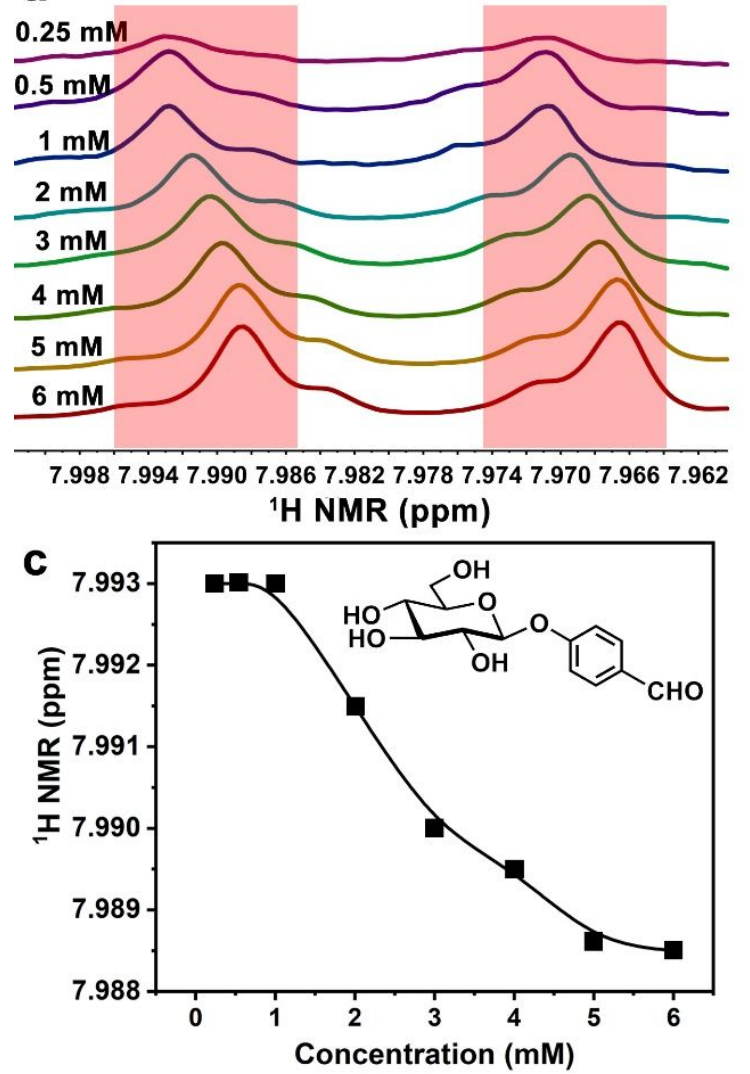

b
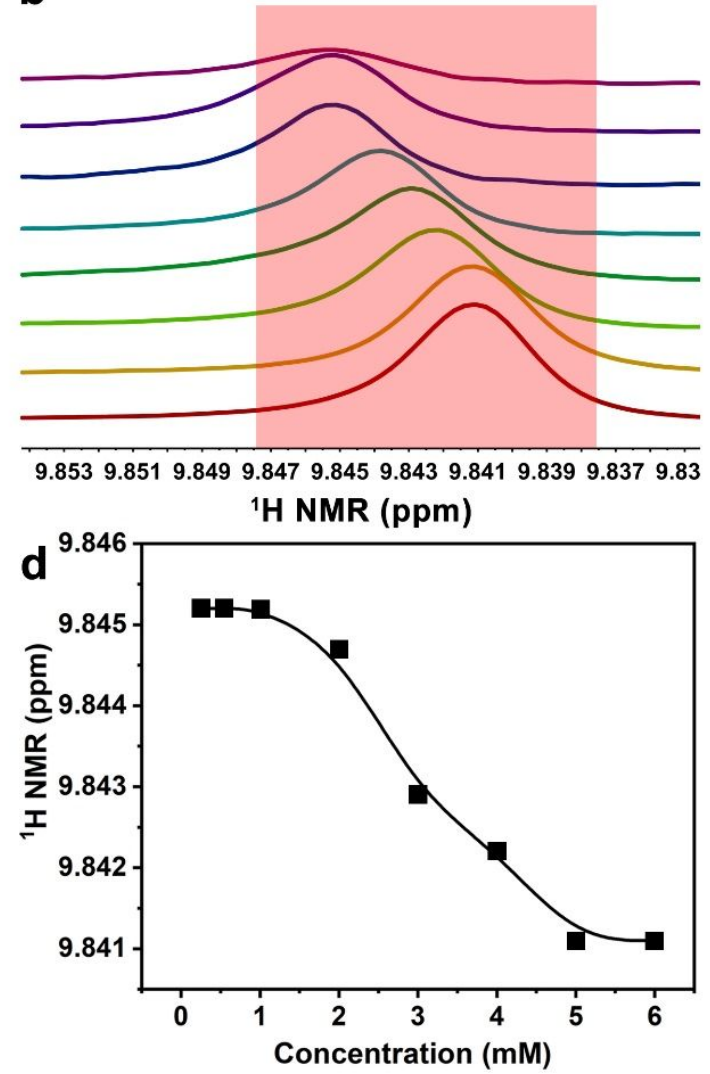

Figure S22. ${ }^{1} \mathrm{H}$ NMR titration experiments to study the self-assembly behavior of 4-formylphenyl $\beta$-D-glucopyranoside by monitoring chemical shift changes of the aromatic protons of 4formylphenyl $\beta$-D-glucopyranoside with different concentrations. (a, b) Partial ${ }^{1} \mathrm{H}$ NMR spectra of 4-formylphenyl $\beta$-D-glucopyranoside at different concentrations in $\mathrm{D}_{2} \mathrm{O}$ at $20^{\circ} \mathrm{C}$, (a) $7.96-8.00$ ppm region; (b) 9.83-9.85 ppm region. (c, d) Concentration-dependent chemical shift changes of the protons of 4-formylphenyl $\beta$-D-glucopyranoside in $\mathrm{D}_{2} \mathrm{O}$ at $20^{\circ} \mathrm{C}$, (c) aromatic proton; (d) aldehyde proton. 


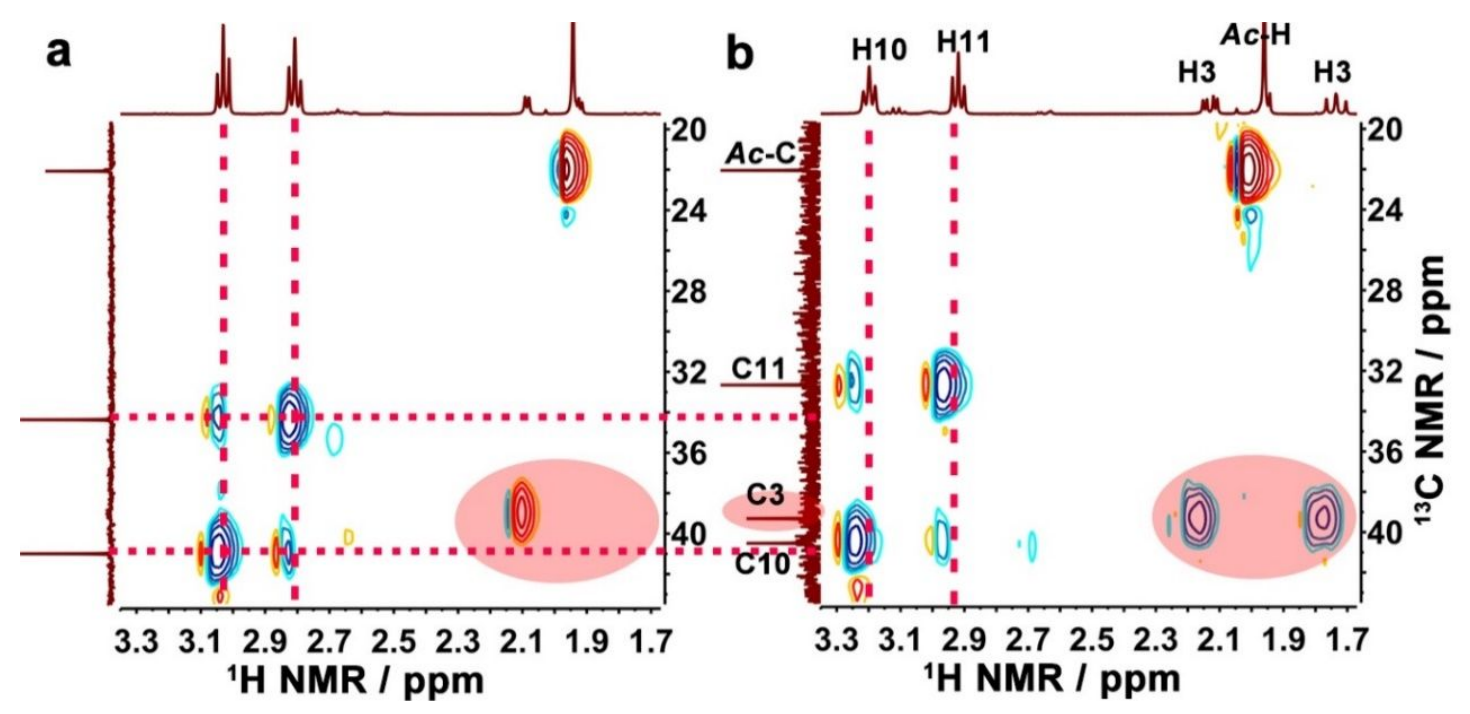

Figure S23. Comparison of partial ${ }^{1} \mathrm{H}-{ }^{13} \mathrm{C}$ COSY NMR spectra of the PEA-Neu5Ac mixture (a) and PEA-Neu5Ac complex (b) in $\mathrm{D}_{2} \mathrm{O}$ at $20^{\circ} \mathrm{C}$, concentrations: $10 \mathrm{mg} \cdot \mathrm{mL}^{-1}$. The difference between these two species are indicated by red regions in the spectra. ${ }^{1} \mathrm{H}-{ }^{13} \mathrm{C}$ COSY NMR spectra provided additional evidence for the configurational difference between the PEA-Neu5Ac mixture (a) and their mixture (b) in $\mathrm{D}_{2} \mathrm{O}$. For example, the signals of $\mathrm{C}-3$ and its coupling with proton at C-3 position (H-3) were observed clearly for the PEA-Neu5Ac complex. However, these signals could not be observed for the PEA-Neu5Ac mixture. And, the chemical shifts of C-11, H-10, and H-11 between the PEA-Neu5Ac complex and their mixture were different, as illustrated by the red dashed lines. 


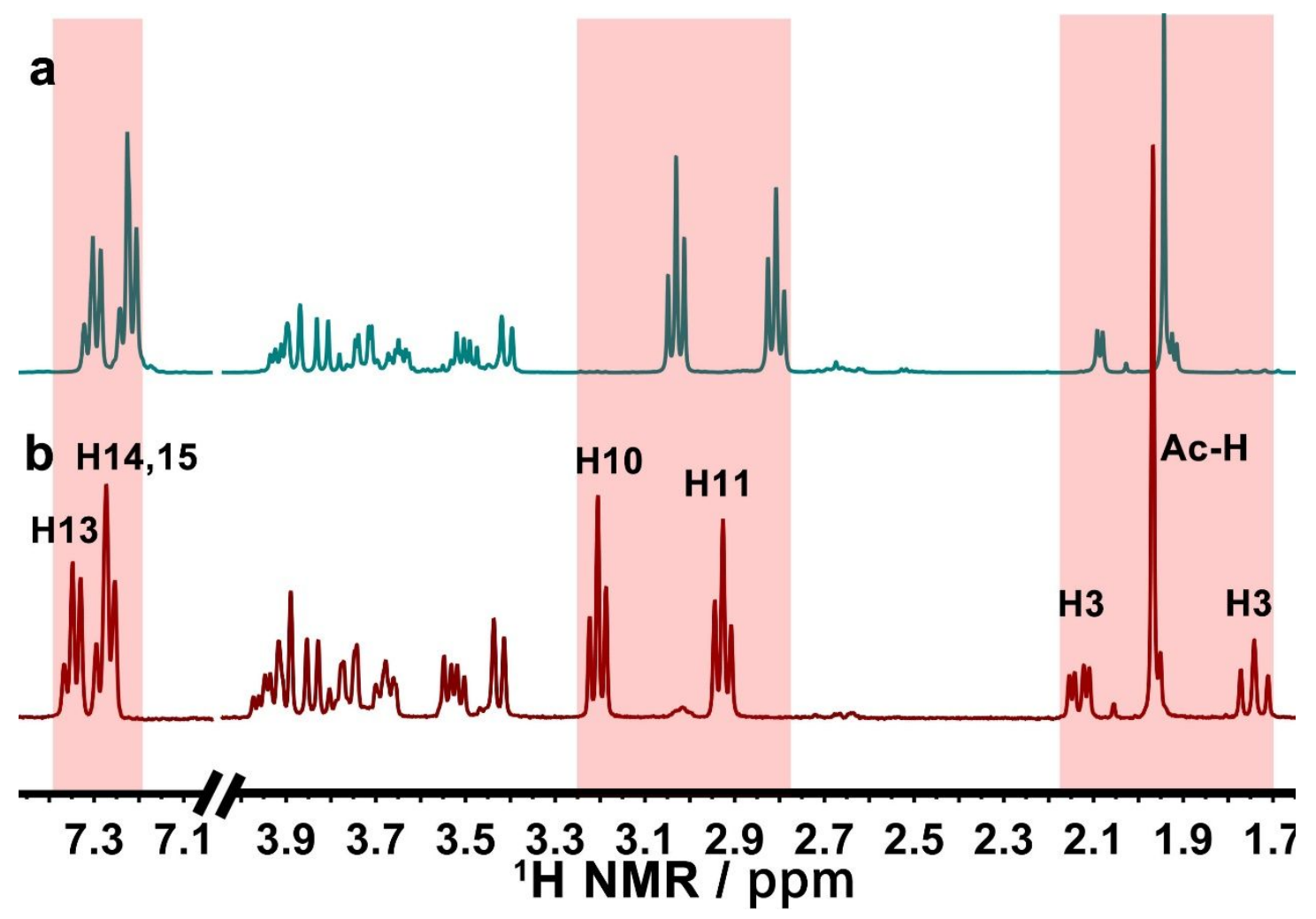

Figure S24. Comparison of ${ }^{1} \mathrm{H}$ NMR spectra of PEA-Neu5Ac mixture (a) and PEA-Neu5Ac complex (b) in $\mathrm{D}_{2} \mathrm{O}$ at $20^{\circ} \mathrm{C}$, concentrations: $10 \mathrm{mg} \cdot \mathrm{mL}^{-1}$. The difference between these two species are indicated by red regions in the ${ }^{1} \mathrm{H}$ NMR spectra. 


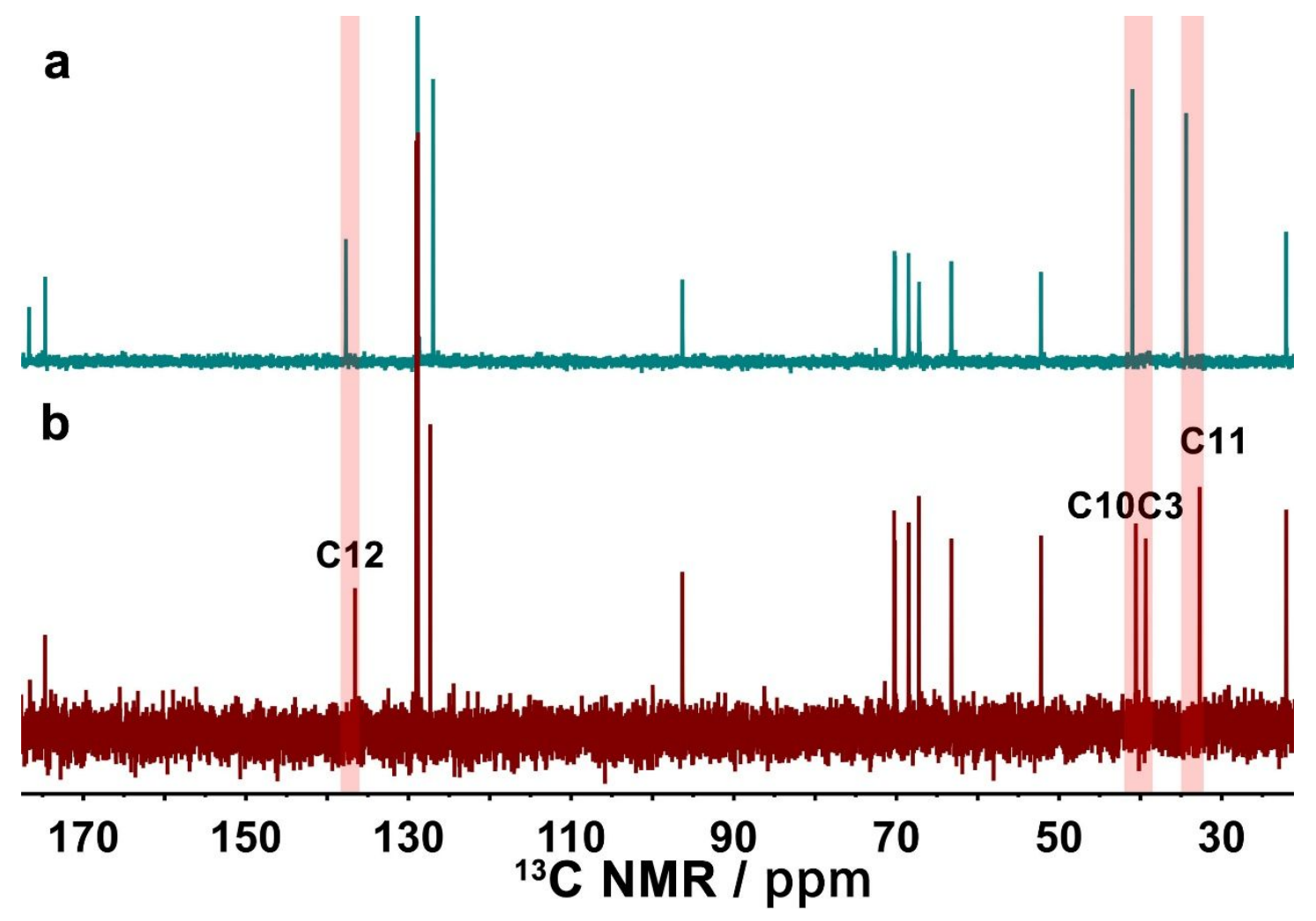

Figure S25. Comparison of ${ }^{13} \mathrm{C}$ NMR spectra of PEA-Neu5Ac mixture (a) and PEA-Neu5Ac complex (b) in $\mathrm{D}_{2} \mathrm{O}$ at $20{ }^{\circ} \mathrm{C}$, concentrations: $40 \mathrm{mg} \cdot \mathrm{mL}^{-1}$. The difference between these two species are indicated by red regions in the ${ }^{13} \mathrm{C}$ NMR spectra. 

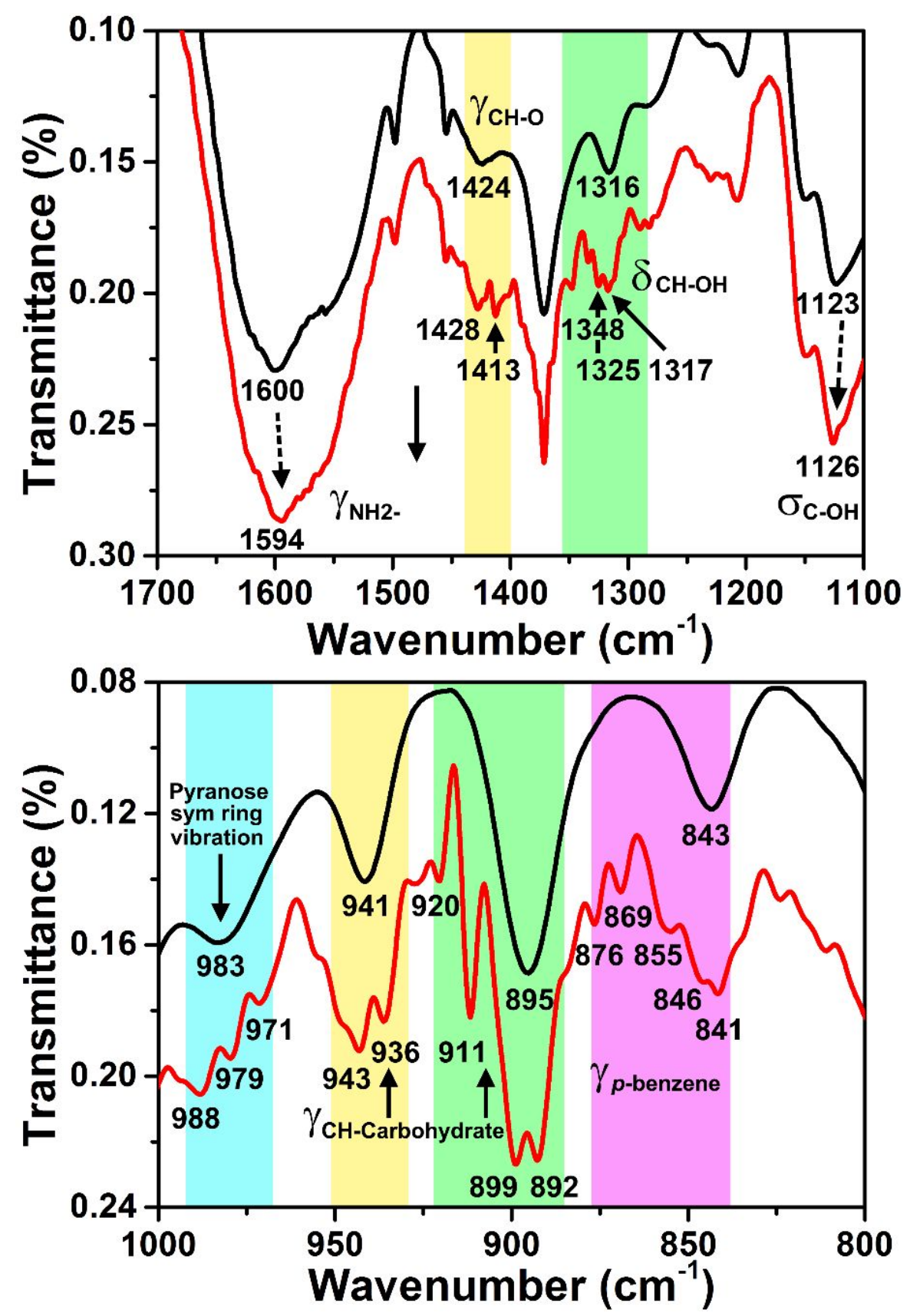

Figure S26. Comparison of partial FT-IR spectra of PEA-Neu5Ac complex (red), and PEA-

Neu5Ac mixture (black). The difference between these two species are indicated by colour regions in the FT-IR spectra. 
Table S1. The experimental conditions of glycopeptide enrichment by Glu-Schiff base@ $\mathrm{SiO}_{2}$

\begin{tabular}{|c|c|c|c|c|}
\hline $\begin{array}{c}\text { Fetuin:BSA } \\
\text { (mol:mol) }\end{array}$ & $\begin{array}{c}\text { Material } \\
\text { weight }\end{array}$ & Loading buffer & Washing solution & Elution solution \\
\hline $\mathbf{1 : 1 0}$ & $1 \mathrm{mg}$ & $\begin{array}{c}85 \% \mathrm{CH}_{3} \mathrm{CN} / 1 \% \mathrm{FA}, \\
24 \mu \mathrm{L}\end{array}$ & $80 \% \mathrm{CH}_{3} \mathrm{CN} / 1 \% \mathrm{FA}, 80 \mu \mathrm{L}$ & $\begin{array}{c}10 \% \mathrm{NH}_{3} \cdot \mathrm{H}_{2} \mathrm{O}, 20 \\
\mu \mathrm{L}\end{array}$ \\
\hline $\mathbf{1 : 2 0 0}$ & $1 \mathrm{mg}$ & $\begin{array}{c}85 \% \mathrm{CH}_{3} \mathrm{CN} / 1 \% \mathrm{FA}, \\
400 \mu \mathrm{L}\end{array}$ & $\begin{array}{c}82 \% \mathrm{CH}_{3} \mathrm{CN} / 1 \% \mathrm{FA}, 40 \mu \mathrm{L} ; \\
80 \% \mathrm{CH}_{3} \mathrm{CN} / 1 \% \mathrm{FA}, 40 \mu \mathrm{L}\end{array}$ & $\begin{array}{c}10 \% \mathrm{NH}_{3} \cdot \mathrm{H}_{2} \mathrm{O}, 20 \\
\mu \mathrm{L}\end{array}$ \\
\hline $\mathbf{1 : 5 0 0 0}$ & $4 \mathrm{mg}$ & $\begin{array}{c}85 \% \mathrm{CH}_{3} \mathrm{CN} / 1 \% \mathrm{FA}, \\
54 \mathrm{~mL}\end{array}$ & $80 \% \mathrm{CH}_{3} \mathrm{CN} / 1 \% \mathrm{FA}, 1000 \mu \mathrm{L} ;$ & $10 \% \mathrm{NH}_{3} \cdot \mathrm{H}_{2} \mathrm{O} 20$ \\
& & $78 \mathrm{CH}_{3} \mathrm{CN} / 1 \% \mathrm{FA}, 500 \mu \mathrm{L}$ & $\mu \mathrm{L}$ \\
\hline
\end{tabular}


Table S2. List of identified glycopeptide information for the fetuin enrichment experiment.

\begin{tabular}{|c|c|c|c|c|c|c|c|c|}
\hline NO. & Position & Peptide sequence & $\begin{array}{l}\text { peptide } \\
\text { mass }\end{array}$ & Glycan & $\begin{array}{l}\text { glycan } \\
\text { mass }\end{array}$ & $\begin{array}{l}\text { glycopeptide } \\
\text { mass M+ }\end{array}$ & & \\
\hline \multirow{3}{*}{ P1 } & \multirow{3}{*}{$72-103$} & \multirow{3}{*}{$\begin{array}{l}\text { ETTCHVLDPTPLA } \\
\text { NCSVR(Cys_CAM: } \\
89,100)\end{array}$} & \multirow{3}{*}{3671.7679} & $\begin{array}{l}{[\mathrm{Hex}] 5[\mathrm{HexNAc}] 4[} \\
\text { NueAC }] 2\end{array}$ & 2224.1798 & $\begin{array}{l}1470.1340 \\
(4+)\end{array}$ & & \\
\hline & & & & $\begin{array}{l}{[\mathrm{Hex}] 6[\mathrm{HexNAc}] 5[} \\
\text { NueAC }] 3\end{array}$ & 2880.8197 & $\begin{array}{l}1307.5349 \\
(5+)\end{array}$ & $\begin{array}{l}1634.2106 \\
(4+)\end{array}$ & $\begin{array}{l}1643.6970 \\
(4+)\end{array}$ \\
\hline & & & & $\begin{array}{l}{[\text { Hex }] 6[\text { HexNAc }] 5[} \\
\text { NueAC }] 4\end{array}$ & 3172.0896 & $\begin{array}{l}1707.2074 \\
(4+)\end{array}$ & & \\
\hline \multirow{3}{*}{ P2 } & \multirow{3}{*}{$144-159$} & \multirow{3}{*}{$\begin{array}{l}\text { KLCPDCPLLAPLN } \\
\text { DSR }\end{array}$} & \multirow{3}{*}{1754.8927} & $\begin{array}{l}{[\mathrm{Hex}] 5[\mathrm{HexNAc}] 4[} \\
\text { NueAC }] 2\end{array}$ & 2224.1798 & $\begin{array}{l}1321.2020 \\
(3+)\end{array}$ & $\begin{array}{l}1326.5676 \\
(3+)\end{array}$ & \\
\hline & & & & $\begin{array}{l}{[\mathrm{Hex}] 5[\mathrm{HexNAc}] 4[} \\
\text { NueAC }] 3\end{array}$ & 2515.4497 & $\begin{array}{l}1423.9211 \\
(3+)\end{array}$ & $\begin{array}{l}1430.6095 \\
(3+)\end{array}$ & $\begin{array}{l}1333.5100 \\
(3+)\end{array}$ \\
\hline & & & & $\begin{array}{l}{[\mathrm{Hex}] 6[\mathrm{HexNAc}] 5[} \\
\text { NueAC }] 3\end{array}$ & 2880.8197 & $\begin{array}{l}1497.4103 \\
(3+)\end{array}$ & & \\
\hline \multirow{5}{*}{ P3 } & \multirow{5}{*}{$144-159$} & \multirow{5}{*}{$\begin{array}{l}\text { KLCPDCPLLAPLN } \\
\text { DSR (Cys_CAM: } \\
146,149)\end{array}$} & \multirow{5}{*}{1868.9357} & {$[\mathrm{Hex}] 5[\mathrm{HexNAc}] 6$} & 2353.2897 & $\begin{array}{l}1305.8552 \\
(3+)\end{array}$ & & \\
\hline & & & & {$[\mathrm{Hex}] 7[\mathrm{HexNAc}] 5$} & 2169.17 & $\begin{array}{l}1340.8479 \\
(3+)\end{array}$ & $\begin{array}{l}1346.5240 \\
(3+)\end{array}$ & $\begin{array}{l}1348.1790 \\
(3+)\end{array}$ \\
\hline & & & & {$[\mathrm{Hex}] 6[\mathrm{HexNAc}] 6$} & 2210.22 & $\begin{array}{l}1354.2119 \\
(3+)\end{array}$ & & \\
\hline & & & & $\begin{array}{l}{[\mathrm{Hex}] 5[\mathrm{HexNAc}] 4[} \\
\text { NueAC }] 2\end{array}$ & 2224.1798 & $\begin{array}{l}1359.2081 \\
(3+)\end{array}$ & & \\
\hline & & & & $\begin{array}{l}{[\mathrm{Hex}] 6[\mathrm{HexNAc}] 5[} \\
\text { NueAC }] 1\end{array}$ & 2298.2799 & $\begin{array}{l}1389.5387 \\
(3+)\end{array}$ & & \\
\hline
\end{tabular}




\begin{tabular}{|c|c|c|c|c|c|c|c|c|}
\hline NO. & Position & Peptide sequence & $\begin{array}{l}\text { peptide } \\
\text { mass }\end{array}$ & Glycan & $\begin{array}{l}\text { glycan } \\
\text { mass }\end{array}$ & $\begin{array}{l}\text { glycopeptide } \\
\text { mass } \mathbf{M}+\end{array}$ & & \\
\hline & & & & $\begin{array}{l}{[\mathrm{Hex}] 6[\mathrm{HexNAc}] 5[} \\
\text { NueAC }] 3\end{array}$ & 2880.8197 & $\begin{array}{l}1577.9752 \\
(3+)\end{array}$ & $\begin{array}{l}1183.5150 \\
(4+)\end{array}$ & $\begin{array}{l}1583.6727 \\
(3+)\end{array}$ \\
\hline \multirow{6}{*}{ P4 } & \multirow{6}{*}{$145-159$} & \multirow{6}{*}{$\begin{array}{l}\text { LCPDCPLLAPLNDS } \\
\text { R (Cys_CAM: 146, } \\
\text { 149) }\end{array}$} & \multirow{6}{*}{1740.8407} & $\begin{array}{l}{[\mathrm{Hex}] 5[\mathrm{HexNAc}] 4[} \\
\text { NueAC }] 1\end{array}$ & 1932.9099 & $\begin{array}{l}1219.1306 \\
(3+)\end{array}$ & & \\
\hline & & & & $\begin{array}{l}{[\mathrm{Hex}] 5[\mathrm{HexNAc}] 4[} \\
\text { NueAC }] 2\end{array}$ & 2224.1798 & $\begin{array}{l}1316.1981 \\
(3+)\end{array}$ & & \\
\hline & & & & $\begin{array}{l}{[\mathrm{Hex}] 5[\mathrm{HexNAc}] 5[} \\
\text { NueAC }] 3\end{array}$ & 2880.8197 & $\begin{array}{l}1535.2697 \\
(3+)\end{array}$ & $\begin{array}{l}1547.9225 \\
(3+)\end{array}$ & \\
\hline & & & & $\begin{array}{l}{[\mathrm{Hex}] 5[\mathrm{HexNAc}] 4[} \\
\text { NueAC }] 3\end{array}$ & 2515.4497 & $\begin{array}{l}1413.2719 \\
(3+)\end{array}$ & $\begin{array}{l}1418.9464 \\
(3+)\end{array}$ & \\
\hline & & & & $\begin{array}{l}{[\mathrm{Hex}] 6[\mathrm{HexNAc}] 5[} \\
\text { NueAC }] 1\end{array}$ & 2298.2799 & $\begin{array}{l}1341.2272 \\
(3+)\end{array}$ & & \\
\hline & & & & $\begin{array}{l}{[\mathrm{Hex}] 6[\mathrm{HexNAc}] 5[} \\
\text { NueAC }] 2\end{array}$ & 2589.5498 & $\begin{array}{l}1438.2662 \\
(3+)\end{array}$ & & \\
\hline P5 & $160-187$ & $\begin{array}{l}\text { VVHAVEVALATFN } \\
\text { AESNGSY } \\
\text { LQLVEISR }\end{array}$ & 3016.5738 & {$[\mathrm{Hex}] 3[\mathrm{HexNAc}] 2$} & 910.9000 & $\begin{array}{l}1311.1725 \\
(3+)\end{array}$ & & \\
\hline \multirow[b]{2}{*}{ P6 } & \multirow[b]{2}{*}{ 246-306 } & $\begin{array}{l}\text { VTCTLFQTQPVIPQ } \\
\text { PQPDGAEAEAPSA }\end{array}$ & & $\begin{array}{l}{[\mathrm{Hex}] 3[\mathrm{HexNAc}] 3[} \\
\text { NueAC }] 3\end{array}$ & 1987.9187 & $\begin{array}{l}1597.6620 \\
(5+)\end{array}$ & & \\
\hline & & $\begin{array}{l}\text { VPDAAGPTPSAAG } \\
\text { PPVASVVVGPSVV } \\
\text { AVPLPLHR } \\
\text { (Cys_CAM: 248) }\end{array}$ & 6015.1323 & $\begin{array}{l}{[\mathrm{Hex}] 4[\mathrm{HexNAc}] 4[} \\
\text { NueAC }] 4\end{array}$ & 2642.9206 & $\begin{array}{l}1729.2660 \\
(5+)\end{array}$ & & \\
\hline P7 & $145-159$ & $\begin{array}{l}\text { LCPDCPLLAPLNDS } \\
\mathrm{R}\end{array}$ & 1626.7978 & $\begin{array}{l}{[\mathrm{Hex}] 5[\mathrm{HexNAc}] 4[} \\
\text { NueAC }] 3\end{array}$ & 2515.4497 & $\begin{array}{l}1375.5366 \\
(3+)\end{array}$ & $\begin{array}{l}1382.9067 \\
(3+)\end{array}$ & $\begin{array}{l}1388.1809 \\
(3+)\end{array}$ \\
\hline
\end{tabular}


Table S3. The enriched and identified glycosylation sites from human serum with Glu-Schiff base@ $\mathrm{SiO}_{2}$.

This data is listed as an individual Excel file!

Table S4. Recovery of Glu-Schiff base@ $\mathrm{SiO}_{2}$ material-based enrichment method towards two SGPs [m/z: $983.7892(3+)$ and $1475.0836(2+)]$, obtained from three parallel MS measurements.

\begin{tabular}{|c|c|c|c|c|c|c|c|}
\hline & \multicolumn{2}{|c|}{ Monitored ions } & \multirow[b]{2}{*}{ Recovery } & & \multicolumn{2}{|c|}{ Monitored ions } & \multirow[b]{2}{*}{ Recovery } \\
\hline & $\begin{array}{c}983.7892 \\
(3+)\end{array}$ & $\begin{array}{c}987.7397 \\
(3+)\end{array}$ & & & $\begin{array}{c}1475.0836 \\
(2+)\end{array}$ & $\begin{array}{c}1481.0691 \\
(2+)\end{array}$ & \\
\hline 1 & 1133 & 1217 & $92.0 \%$ & 1 & 803 & 778 & $94.7 \%$ \\
\hline 2 & 1016 & 1183 & $84.9 \%$ & 2 & 734 & 747 & $90.1 \%$ \\
\hline 3 & 1088 & 1041 & $102.4 \%$ & 3 & 851 & 766 & $101.9 \%$ \\
\hline $\begin{array}{l}\text { Average } \\
\text { Recovery }\end{array}$ & & & $93.1 \%+8.8 \%$ & $\begin{array}{l}\text { Average } \\
\text { Recovery }\end{array}$ & & & $95.5 \%+5.9 \%$ \\
\hline
\end{tabular}




\section{References}

1. Qing, G. Y.; Lu, Q.; Li, X. L.; Liu, J.; Ye, M. L.; Liang, X. M.; Sun, T. L. Hydrogen bond based smart polymer for highly selective and tunable capture of multiply phosphorylated peptides. Nat. Commun. 2017, 8, 461 .

2. Brisson, E. R. L.; Xiao, Z. Y.; Franks, G. V.; Connal, L. A. Versatile synthesis of amino acid functional polymers without protection group chemistry.

Biomacromolecules 2017, 18, 272-280.

3. Chatziefthimiou, S. D.; Lazarou, Y. G.; Hadjoudis, E.; Dziembowska, T.; Mavridis, I. M. Keto forms of salicylaldehyde schiff bases: structural and theoretical aspects. J. Phys. Chem. B 2006, 110, 23701-23709.

4. Li, M. M.; Qing, G. Y.; Xiong, Y. T.; Lai, Y. K.; Sun, T. L. CH- $\pi$ interaction driven macroscopic property transition on smart polymer surface. Sci. Rep. 2015, 5,15742 .

5. Dong, X. F.; Qin, H. Q.; Mao, J. W.; Yu, D. P.; Li, X. L.; Shen, A. J.; Yan, J. Y.; Yu, L.; Guo, Z. M.; Ye, M. L.; Zou, H. F.; Liang, X. M. In-depth analysis of glycoprotein sialylation in serum using a dual-functional material with superior hydrophilicity and switchable surface charge. Anal. Chem. 2017, 89, 3966-3972.

6. Sun, Z.; Qin, H. Q.; Wang, F. J.; Cheng, K.; Dong, M. M.; Ye, M. L.; Zou. H. F. Capture and dimethyl labeling of glycopeptides on hydrazide beads for quantitative glycoproteomics analysis. Anal. Chem. 2012, 84, 8452- 8456.

7. Velazquez-Campoy, A.; Freire, E. Isothermal titration calorimetry to determine association constants for high-affinity ligands. Nat. Protoc. 2006, 1, 186-191.

8. Huhtamaki, T.; Tian, X. L.; Korhonen, J. T.; Ras, R. H. A. Surface-wetting characterization using contact-angle measurements. Nat. Protoc. 2018, 13, 15211538.

9. Engel, A.; Lyubchenko, Y.; Muller, D. Atomic force microscopy: a powerful tool to observe biomolecules at work. Trends Cell Biol. 1999, 9, 77-80. 
10. Febles, N. K.; Ferrie, A. M.; Fang, Y. Label-free single cell kinetics of the invasion of spheroidal colon cancer cells through 3D matrigel. Anal. Chem. 2014, $86,8842-8849$.

11. Lee, P. C.; Meisel, D. Adsorption and surface-enhanced raman of dyes on silver and god sols. J. Phys. Chem. 1982, 86, 3391-3395.

12. Xie, D.; Zhu, W. F.; Cheng, H.; Yao, Z. Y.; Li, M.; Zhao, Y. L. An antibody-free assay for simultaneous capture and detection of glycoproteins by surface enhanced Raman spectroscopy. Phys. Chem. Chem. Phys. 2018, 20, 8881-8886. 